\title{
Characteristics of aerosols over Hyderabad in southern Peninsular India: synergy in the classification techniques
}

\author{
P. R. Sinha ${ }^{1}$, D. G. Kaskaoutis ${ }^{2}$, R. K. Manchanda ${ }^{1}$, and S. Sreenivasan ${ }^{1}$ \\ ${ }^{1}$ National Balloon Facility, Tata Institute of Fundamental Research, ECIL Post 5, Hyderabad - 500 062, India \\ ${ }^{2}$ Research and Technology Development Center, Sharda University, Greater Noida, NCR - 201306, India \\ Correspondence to: P. R. Sinha (prs@tifr.res.in)
}

Received: 10 December 2011 - Revised: 30 July 2012 - Accepted: 3 September 2012 - Published: 27 September 2012

\begin{abstract}
The present study focuses on analyzing the seasonal changes in aerosol characteristics using a classification scheme proposed by Gobbi et al. (2007). This scheme is based on the correlation between the Ångström exponent $(\alpha)$ in the $440-870 \mathrm{~nm}$ range and the difference in $\alpha$ values $[d \alpha=\alpha(440-675-\alpha(675-870)]$ including the size of finemode particles $\left(R_{\mathrm{f}}\right)$ and the fine-mode fraction $(\eta)$. The classification scheme can therefore provide information on the aerosol characteristics and their modification in transit. Spectral aerosol measurements using the Microtops-II sun photometer (MT-II) have systematically been conducted in Hyderabad, India during April 2009-March 2010 and analysed to study the seasonal effects. The results reveal a seasonal dependence, i.e. the presence of fine-mode aerosols under turbid atmospheres in winter and post-monsoon, a mixture of fine and coarse aerosol types in pre-monsoon and a significant influence of marine mixed with dust air masses during the monsoon season. The identification of the aerosol source type and the modification processes are discussed along with clustered air-mass trajectory analysis. Furthermore, we have also checked the consistency of this scheme with the findings arrived from the columnar size distributions (CSDs) computed by numerical inversion of spectral AOD using King's inversion algorithm and the scatter plot between AOD and spectral $\alpha$. The comparison clearly demonstrates the usefulness of the classification scheme and highlights its advantages for the monitoring and study of seasonal variation of the aerosol types and the modification processes in the atmosphere.
\end{abstract}

Keywords. Atmospheric composition and structure (Aerosols and particles)

\section{Introduction}

Atmospheric aerosols affect the global climatic system in many ways, i.e. by attenuating the solar radiation reaching the ground, modifying the solar spectrum, re-distributing the earth-atmosphere energy budget and influencing cloud microphysics and hydrological cycle (IPCC, 2007). Although the aerosol optical properties have now been well known, large uncertainties are still associated with the aerosol climate implications due to the variety of the aerosol types, the changing optical and physicochemical properties, the influence of dynamic and synoptic meteorology and the mixing (internal and external) processes in the atmosphere.

The aerosols over the Indian sub-continent can be a mix of various types, i.e. anthropogenic aerosols from the urban centers, biomass burning from seasonal forest fires or crop residue burning, desert dust produced in the Thar desert or transported by Arabia and Middle East and marine aerosols from the adjoining oceans during the southwest summer monsoon. Due to large diversity in population density, regional emissions, land use and seasonally-changed air masses, the aerosol load, optical properties and their climate implications present large variation over India, both spatially and temporally (Lawrence and Lelieveld, 2010). Emphasizing these, several experimental campaigns (e.g. INDOEX, ARMEX, LC-I, LC-II, ICARB, W-ICARB, ARFI, ARFIRAWEX, CAIPEEX) along with land, ship cruise, aircraft and satellite measurements have been carried out to characterize the aerosols over the Indian sub-continent and adjoining oceanic areas (Ramanathan et al., 2001; Moorthy et al., 2005, 2009; Jayaraman et al., 2006; Babu et al., 2011; Sinha et al., 2011; Chakravarty et al., 2011). However, the periodic campaigns are essential to study the small scale features, time 


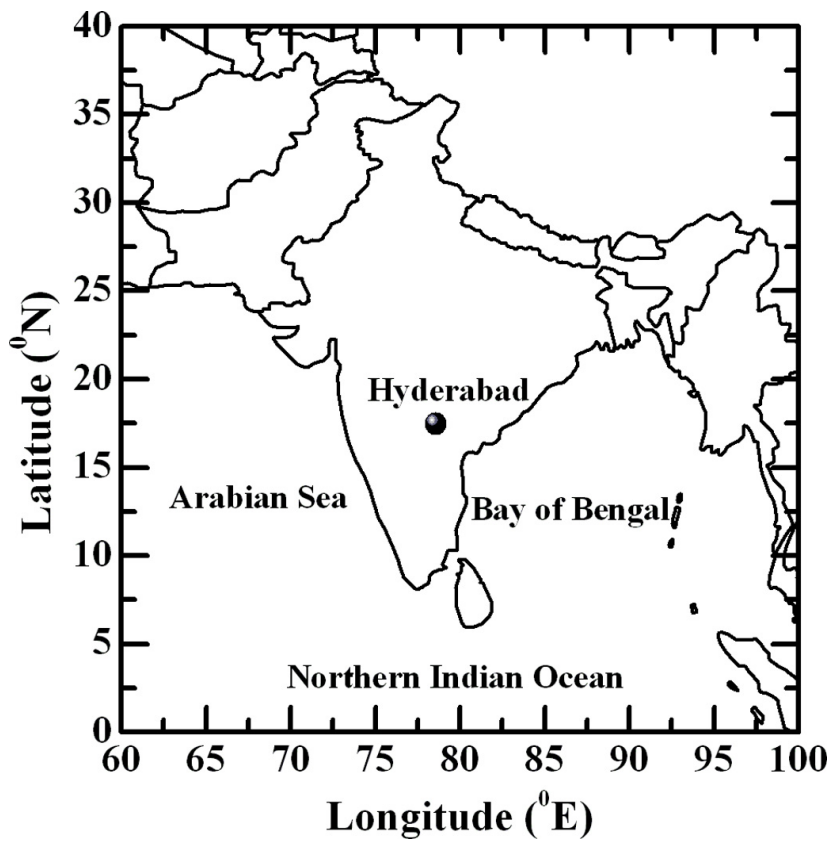

Fig. 1. Terrain of Peninsular India and location of measurement site.

variation, seasonal effects and spatial gradients for the climatic impact in terms of changes in radiative forcing, local and regional meteorology and air-mass origin.

The rapid industrialisation in Hyderabad and its growth as a mega city, the adverse consequences of increased industrial activity and the general economic prosperity are the emission of large amounts of black carbon, trace gases and various precursor gases, which are emitted from vehicular and industrial emissions in this region. The unique geographical location of Hyderabad $\left(17.47^{\circ} \mathrm{N}, 78.58^{\circ} \mathrm{E}\right)$ in the south peninsula of India makes it an ideal site for detailed studies of the rich mixtures of aerosol transported from deserts, Indo-Gangetic plain and the surrounding oceanic regions in addition to the local emissions. The aerosols over Hyderabad a are mix of both natural origin, such as marine particles and mineral or desert dust, and anthropogenic origin, such as industrial emissions, fossil fuel combustion, automobile exhausts and from other human activities.

The atmospheric physical processes such as coagulation, growth by aging and humidification, gas-to-particle conversion, long-range transport and deposition of the aerosol particles in the atmosphere modify the aerosol size distribution, vertical and columnar properties. To understand the underlying processes which modify the distribution of aerosols in the atmosphere is of great importance for climatic studies. The present work examines the aerosol optical properties and the changes in the aerosol characteristics using the classification scheme based on the measured scattering properties $(\alpha, d \alpha)$ derived from the MT-II data. Since the light scattering and absorption efficiency of the aerosol particles are a function of their size, shape and composition, a relationship between the
Ångström exponent $(\alpha)$ and its variation with wavelength can help determine the aerosol characteristics (Eck et al., 1999, 2012). Gobbi et al. (2007) proposed a classification scheme for the monitoring the aerosol properties and the modification processes by combining $\alpha$ and its spectral variation $(d \alpha)$ with the radius of fine-mode particles $\left(R_{\mathrm{f}}\right)$ and the finemode fraction $(\eta)$ as the grid parameters in grouped AOD. The scheme applied to eight different AERONET stations in three continents revealed different aerosol modification processes depending on the aerosol types and compositions. This technique was further applied for aerosol characterization of different AERONET data sets obtained from Northern Africa, Northeastern Atlantic, Mediterranean Basin and the Middle East (Basart et al., 2009) in Arabian Sea and Bay of Bengal during ICARB and W-ICARB cruise campaigns, (Kaskaoutis et al., 2010, 2011).

In the present work, we make the first ever attempt to apply the classification scheme developed by Gobbi et al. (2007) for characterization of the aerosols over Hyderabad, India. One year measurements of the quality-assured and well calibrated MT-II database were used for this study. The data were analysed both collectively and on seasonal basis to discern dominant aerosol types in each season and the changes in the properties caused by physical processes, e.g. coagulation, growth by aging and humidification, gas-to-particle conversion, etc., over the study site. This study further investigates the consistency between classification scheme and other techniques for the study of aerosol characteristics and highlights its usefulness and comparative advantages.

\section{Study location, instrumentation}

The measurements were carried out in the premises of the National Balloon Facility of Tata Institute of Fundamental Research (TIFR) Campus $\left(17.47^{\circ} \mathrm{N}, 78.58^{\circ} \mathrm{E}\right)$ located at $\sim 15 \mathrm{~km}$ from the urban center of Hyderabad, in the northeast edge of the city (Fig. 1). An increase in a high capacity coal thermal power plant in the premises of the Hyderabad city and the increased number of vehicles are the main factors influencing the anthropogenic aerosol (sulfates, nitrates and black carbon) and trace gases (mainly $\mathrm{NO}_{\mathrm{x}}$ ) emissions (Gummeneni et al., 2011; Prasad et al., 2006, 2011). The geographical location of Hyderabad makes it an ideal site for studying the mixtures of aerosols transported from deserts, Indo-Gangetic Plains (IGP) and oceans, in addition to the local emissions. The climate of the area follows the Indian monsoon system with a dry season during winter (December-February) and pre-monsoon (March-May) and a wet season in monsoon (June-September). Post-monsoon (October-November) is a transition season with sparse rainfall. The air masses that affect the area change their directions seasonally, thus being responsible for long-range transport of aerosols of different origin and characteristics. For example, during winter the wind speed is low and the locally produced 
anthropogenic aerosols are a well-mixed aerosol type, in premonsoon season that both dust and biomass-burning plumes affect Hyderabad on certain occasions, thus producing a rich mixture of both coarse and fine aerosols. During monsoon the low-altitude air masses are a mixture of oceanic and the desert thus producing a mixture of marine and dust aerosols, while in a post-monsoon period, the atmospheric circulation is similar to winter. The local and regional meteorology (humidity, wind speed and direction) also affects the aerosol optical and physicochemical properties, but such a detailed description is beyond the scope of the present study.

The spectral AOD measurements were conducted during cloudless conditions from April 2009 to March 2010 using the MT-II and ozonometer that measures the direct-beam irradiance at 7 wavelengths; six of them $(380,440,500$, $675,870,936$ and $1020 \mathrm{~nm}$ ) are used for aerosol retrievals, while the 7th at $936 \mathrm{~nm}$ for retrievals of water vapor content (WVC). The aerosol retrievals are performed from the instantaneous solar flux measurements using the instrument's internal calibration. The field of view (FOV) of the instrument is $\sim 2.5^{\circ}$, while the full width at half maximum (FWHM) bandwidth at each of the AOD channels is $2.4 \pm 0.4 \mathrm{~nm}$. Typical errors in AOD measurements from MT-II are $\sim 0.03$ (Morys et al., 2001). The scope of the study necessitates high accuracy in the AOD retrievals, since any bias may have a large effect on the computed parameters ( $\alpha, d \alpha$ and CSDs). Thus, perturbed irradiance measurements due to possible cloud contamination caused by undetected with naked eye cirrus clouds have been excluded if they conclude to unexpected AOD and Ångström exponent values, i.e. up to two standard deviations from the daily mean value. Furthermore, the method outlined by Cachorro et al. (2004) was applied in order to calibrate the AODs, since an inaccurate calibration can lead to a diurnal cycle of the AOD (mainly in the UV) and produce significant errors in AOD at the miscalibrated wavelength bands. The spectral AODs were obtained every $30 \mathrm{~min}$ starting from 07:00 in the morning till 05:30 $(\mathrm{LT}=\mathrm{UT}+5: 30)$ in the evening, when the weather conditions are free of clouds and also there are no clouds near to the sun FOV. After excluding the perturbed data, the available data set for each season is 574 for winter, 1013 for pre-monsoon, 775 for monsoon and 864 for post-monsoon.

Since the spectral AOD retrievals from MT-II are based on the instrumental internal calibration. The corrections for molecular scattering, ozone and/or water vapor absorption at specific wavelengths are taken care internally and therefore, the uncertainties due to these effects have a negligible contribution to the AOD. In turn, these uncertainties contribute less than $10 \%$ error in $\alpha$ values. The averaging process further decreases the uncertainties in $\alpha$ or $d \alpha$ values. We have taken extra care in screening the spectral AOD data for any cloud contamination and such measurements were ignored.

\section{Methodology}

The Ångström exponent $(\alpha)$ indicates the spectral variation of AOD and it depends on several parameters, such as the aerosol size distribution, the refractive index, the effective radius, the fine-to-coarse-mode fraction and the wavelength range used for its determination (e.g. Reid et al., 1999; O'Neill et al., 2001). The characterization of aerosols using spectral sun photometry necessitates the combined use of three independent variables: (i) the $\mathrm{AOD}$, (ii) the $\alpha$, and (iii) the wavelength dependence of $\alpha$. The AOD corresponds to the aerosol load in the atmosphere, while $\alpha$ provides the initial information about the particle size. Due to significant dependence of $\alpha$ values on the wavelength, the third variable, i.e. spectral variation of $\alpha$, was introduced to provide additional information about the aerosol size distribution and their types as well as the potential sources. Several studies have been thus performed to classify the aerosol types over the globe, based upon the values of these three parameters (Eck et al., 1999, 2001, 2003; Schuster et al., 2006; Kalapureddy et al., 2009; Kaskaoutis et al., 2007, 2009, 2010, 2011).

Gobbi et al. (2007) proposed a graphical framework to visualise the contribution of fine aerosols to AOD, reveal the modal radius of the fine particles $\left(R_{\mathrm{f}}\right)$ and segregate the aerosol growth by humidification and cloud contamination. In this technique the aerosols are classified by a combination of $\alpha$ vs. $d \alpha$ in several AOD groups superposed over a classification scheme computed using Mie scattering for a complex refractive index of 1.4-0.001i, which is typical for urban/industrial aerosols, fine-mode fraction ( $\left.\eta=\mathrm{AOD}_{\text {fine }} / \mathrm{AOD} \tau_{\text {total }}\right)$ at $675 \mathrm{~nm}$ and $R_{\mathrm{f}}$ for bimodal $\log -$ normal aerosol size distributions.

Gobbi et al. (2007) showed the sensitivity of the classification scheme with the variation in refractive index. Computations showed some clockwise rotation about the origin of the constant radius curves for increasing refractive index; the effect was much weaker in the case of $\eta$. Maximum $R_{\mathrm{f}}$ indetermination is of the order of $\pm 25 \%$ for refractive index varying between $m=1.33-0.0 \mathrm{i}$ and $m=1.53-0.003 \mathrm{i}$, while the $\eta$ spans a range of the order of $\pm 10 \%$. Within this level of indetermination, the scheme is robust enough to provide an operational classification of the aerosol properties.

It is also believed that the non-sphericity of particles does not affect the results significantly (Gobbi et al., 2007). The contribution of non-spherical particles to the AOD is $15 \%$ smaller than the spherical one. The sub-micron non-spherical particles have similar extinction as the spherical ones, leading to minor impact on the Ångström exponent. Furthermore, the extinction by spherical and non-spherical coarsemode particles is similar and the difference in AOD at the wavelengths 440,670 and $870 \mathrm{~nm}$ is $5 \%$ and it approaches zero with increasing particle size (Mishchenko et al., 1997). An important assumption of Gobbi's visualisation scheme is the bimodal aerosol size distribution. The retrieved columnar 
size distributions over Hyderabad revealed the bimodal characteristics. In view of all these discussions, we can expect that Gobbi's visualisation scheme is quite robust for the segregation of aerosol types and their modification processes in the atmosphere.

In order to distinguish the source regions contributing to the observed aerosols during different seasons, 7-day isentropic air-mass back trajectories at $1500 \mathrm{~m}$ above ground level (as $1500 \mathrm{~m}$ could be treated the representative altitude for the aerosol transport in the free atmosphere) were analysed for all the days of MT-II observations using the Hybrid Single Particle Lagrangian Integrated Trajectory model (Draxler and Rolph, 2003) over Hyderabad.

In our analysis the aerosol columnar size distributions (CSDs) were determined from the spectral AOD using the Mie integral equation:

$\tau_{\lambda}=\int_{r_{\mathrm{a}}}^{r_{\mathrm{b}}} \pi r^{2} Q_{\mathrm{ext}}(m, r, \lambda) n_{\mathrm{c}}(r) d r$

where $Q_{\text {ext }}$ is the Mie extinction efficiency, which depends on the spectral complex refractive index $(m)$ of the aerosol particles obtained from Lubin et al. (2002), particle radii $(r)$ and wavelength $(\lambda) ; n_{\mathrm{c}}(r)$ is the aerosol columnar number density (in a vertical column per unit cross-section) within the radius range $d r$ centered at $r$. The $r_{\mathrm{a}}$ and $r_{\mathrm{b}}$ are the lower and upper cutoff radii and their values are selected by evaluating the kernels (integrand of Eq. 1) for the extreme wavelengths used in the MT-II, i.e. from visible (380) to near infra-red $(1020 \mathrm{~nm})$ for different types of aerosol size distribution. The best selection of values of $r_{\mathrm{a}}$ and $r_{\mathrm{a}}$ are found to be 0.05 and $3.0 \mu \mathrm{m}$, respectively.

The $n_{\mathrm{c}}(r)$ was retrieved from the spectral AODs by numerical inversion of Eq. (1) using the linear inversion method of King et al. (1978). The reiterative procedures assumed that $n_{c}(r)$ is height invariant or averaged over the vertical column. After obtaining the CSD, the spectral AODs are reestimated using the Eq. (1) and are compared with the measured ones. The estimated CSDs are accepted only when the reestimated $\mathrm{AOD}_{\lambda}$ agrees with the measured within the measurement errors. The satisfactorily retrievals were obtained after 7-8 iterations with low value $(<0.01)$ of the smoothing factor $\gamma_{\text {rel }}$ (King et al., 1978). The seasonal variation in refractive index is not considered in the inversion since it is based on the measurement of spectral solar radiation rather than the scattered sky radiances and under such former condition the retrieved columnar size distribution show the week dependency on changes in the aerosol refractive index (Gogoi et al., 2009). Furthermore, Eq. (1) has the built in assumption of spherical aerosols; thus, the presence of non-spherical dust aerosols would deviate the results leading to underestimation of the mean and effective radius (e.g. King, 1982; Moorthy et al., 1991). Following this method the CSDs were obtained for each season and AOD group. The effective $R_{\text {eff }}$ is defined as the ratio of the third moment to the second moment of the aerosol number size distribution and is applied for radius range $0.05-0.3 \mu \mathrm{m}$ and is given by

$R_{\mathrm{eff}}=\int_{0.05}^{3} \frac{r^{3} n_{\mathrm{c}}(r) d r}{r^{2} n_{\mathrm{c}}(r) d r}$.

While the columnar number density $\left(N_{\mathrm{T}}\right)$ and the columnar mass loading $\left(m_{\mathrm{L}}\right)$ of aerosols were also calculated from the retrieved CSDs as

$N_{\mathrm{T}}=\int_{0.05}^{3} n_{\mathrm{c}}(r) d r$

$m_{\mathrm{L}}=\frac{4 \pi d}{3} \int_{0.05}^{3} r^{3} n_{\mathrm{c}}(r) d r$

where $d$ is the mean aerosol density defined to $2.2 \mathrm{~g} \mathrm{~cm}^{-3}$ (Pruppacher and Klett, 1978). Furthermore, the columnar amount of accumulation $\left(N_{\mathrm{a}}\right)$ and coarse $\left(N_{\mathrm{c}}\right)$ aerosols were calculated using as threshold radius the $0.5 \mu \mathrm{m}$ :

$N_{\mathrm{a}}=\int_{0.05}^{0.5} n_{\mathrm{c}}(r) d r$

$N_{\mathrm{c}}=\int_{0.5}^{3} n_{\mathrm{c}}(r) d r$.

The derived parameters in each season from the CSD are further discussed along with spectral $\mathrm{AOD}, \alpha$ and $d \alpha$ values in order to see the degree of association within the results obtained using the classification scheme.

\section{Results and discussion}

\subsection{Spectral variation of aerosol optical depth}

The daily averaged values of $\mathrm{AOD}_{500}$ and the Ångström exponent $\left(\alpha_{440-870}\right)$ during the period April 2009-March 2010 over Hyderabad are shown in Fig. 2a. The results reveal sig-

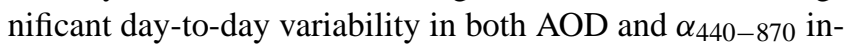
dicating the influence of the local meteorology, variety of aerosol types and sources. The large daily variation in the Ångström exponent suggest significant diurnal variability in particle size distributions ranging from fine-mode dominated events $(\alpha>1.5)$ during post-monsoon and winter, to coarsemode dust events $(\alpha<0.17)$ during monsoon and the mixed aerosol size and type during pre-monsoon season. 

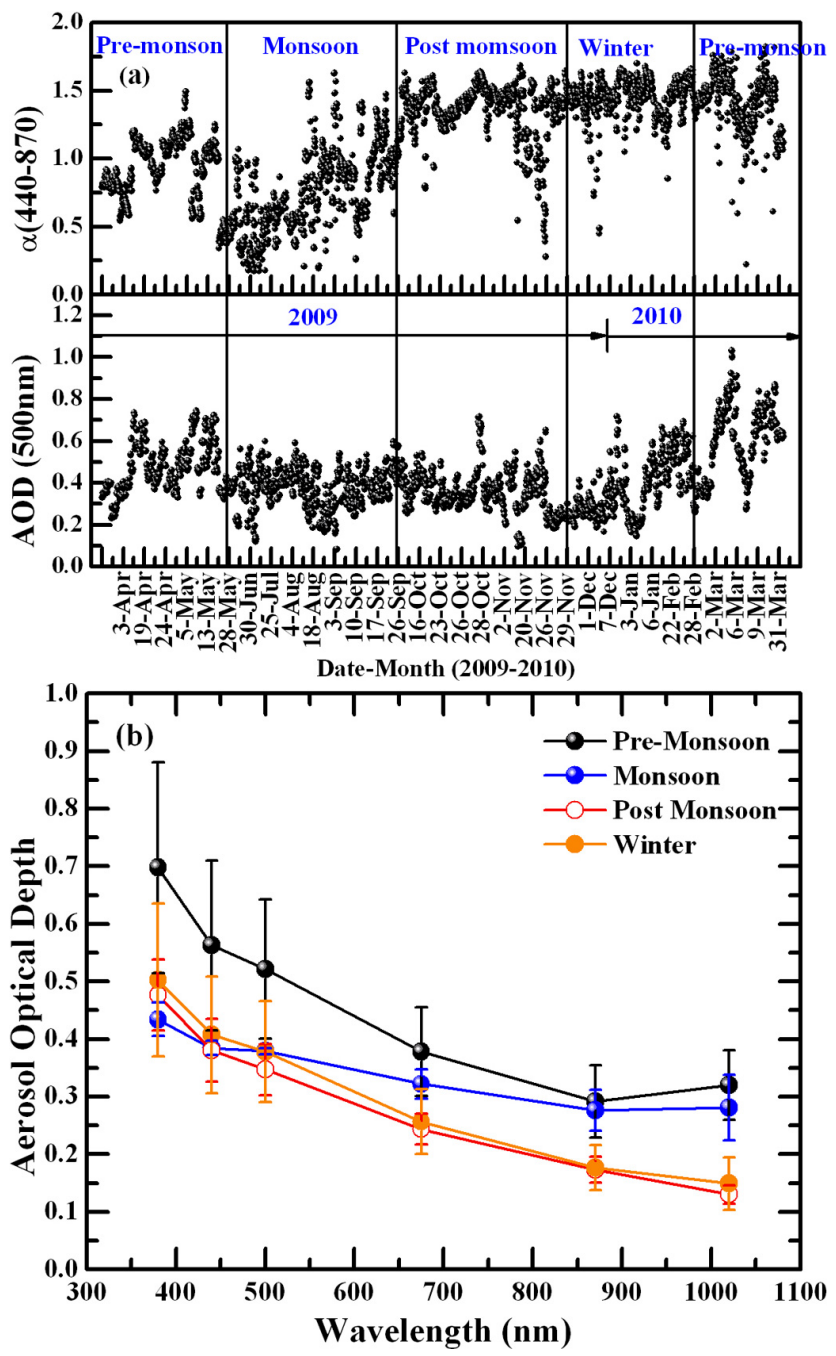

Fig. 2. (a) Daily mean variation of $\mathrm{AOD}_{500}$ and Ångström exponent $(\alpha)$; (b) Seasonal mean spectral AOD variation over Hyderabad during the period April 2009-March 2010.

Spectral variation of the mean seasonal AOD values are presented in Fig. 2b. It can be clearly seen that at shorter wavelengths, the spectral AOD values in pre-monsoon are larger $\left(\mathrm{AOD}_{500}=0.53 \pm 0.12, \alpha=1.11 \pm 0.23\right)$, while at longer wavelengths these are similar to those observed in the monsoon season. During monsoon, the aerosols show a weak spectral dependence $(\alpha=0.67 \pm 0.23)$, while more steep spectra are observed in winter and post-monsoon with mean $\alpha=1.41 \pm 0.15$ and $\alpha=1.26 \pm 0.27$, respectively. The magnitude of the AOD values in winter and post-monsoon seasons is much lower compared to the pre-monsoon season but exhibits higher spectral dependence. The seasonal variation in the spectral dependence as seen in Fig. $2 b$ is mainly caused by the presence of aerosols of different origin and characteristics.

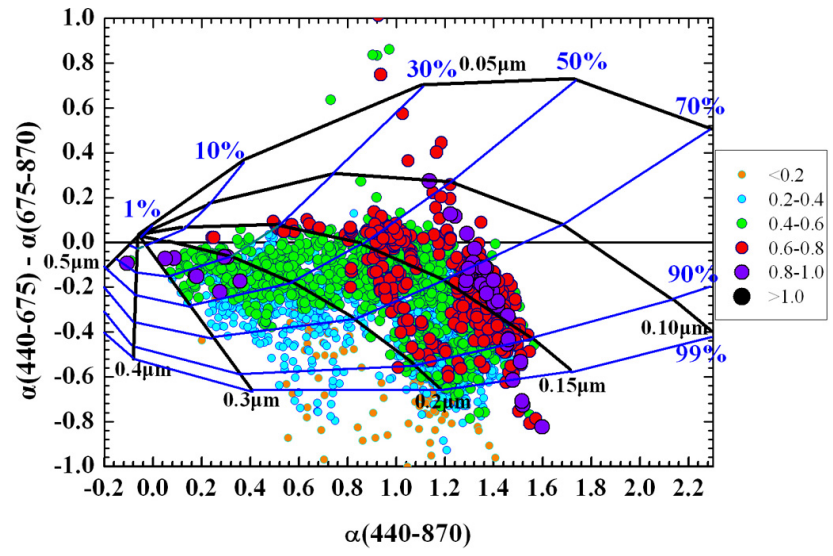

Fig. 3. Ångström exponent difference, $d \alpha=\alpha(440-675)-\alpha(675-$ 870 ), as a function of the $\alpha_{440-870}$ and $\mathrm{AOD}_{500}$ (colour-sized scale) over Hyderabad, for bimodal log-normal size distribution. The black lines indicate the fixed effective radius $\left(\mathrm{R}_{f}\right)$ of the fine mode and the blue lines for a fixed fraction $(\eta)$ of fine mode to the AOD.

\subsection{Classification of aerosols}

The segregation of the aerosols inferred from the MT-II data is shown in Fig. 3. The $\mathrm{x}-$ and $\mathrm{y}$-axis represent $\alpha$ and the difference $(d \alpha)$ in the exponent values in two spectral bands $(440-675 \mathrm{~nm})$ and $(675-870 \mathrm{~nm})$, respectively. The black and blue curves represent the different values of $R_{\mathrm{f}}$ and $\eta$, respectively. The size of the symbol (different colors for better presentation) represents the increasing AOD values. There are several visual criteria which can describe the characteristics of the aerosols using a classification scheme. For example, the negative values of $\mathrm{d} \alpha$ associated with larger $\alpha$ indicate the dominance of fine-mode aerosols, while $d \alpha$ close to zero, or even positive, indicates significant contribution of coarse-mode particles associated with bi-modal size distribution with similar modes. The aerosol modification processes (aging, coagulation, humidification and cloud contamination) both decrease $\alpha$, but they have different characteristics in $\alpha$ vs. $d \alpha$ plot, e.g. the cloud contamination enhances the weight of the coarse mode, while aging, humidification and coagulation increases $R_{\mathrm{f}}$. The increase in AOD with coarse-mode fraction along a constant $R_{\mathrm{f}}$ curve towards the origin ( $\alpha=0, d \alpha=0)$ indicates cloud contamination. Similarly, the increase in AOD towards lower $\alpha$ and smaller negative $d \alpha$ values indicates the dominance of either dust or maritime aerosols or a combination of both. The increase in AOD with $R_{\mathrm{f}}$ and $\eta$ infer the hydration of aerosol particles, while increase in AOD with increasing $R_{\mathrm{f}}$ and decreasing $\alpha$ suggests aging and/or coagulation and, the reverse, i.e. increase in AOD with decreasing $R_{\mathrm{f}}$ and increasing $\alpha$, corresponds to freshly emitted fine aerosols (Gobbi et al., 2007; Basart et al., 2009; Kaskaoutis et al., 2011). Based on the aforementioned criteria the aerosol optical properties and the modification 

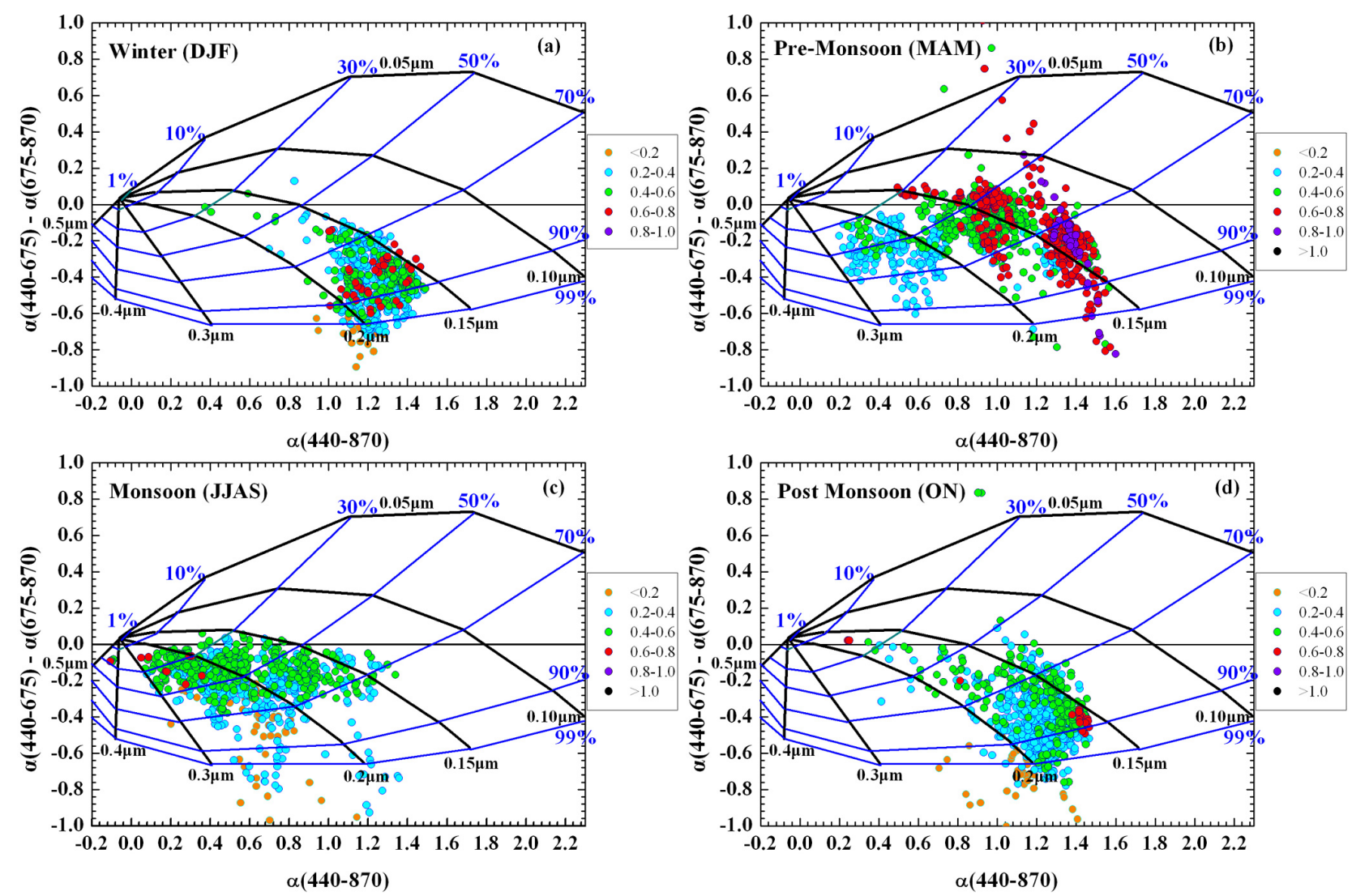

Fig. 4. Same as Fig. 3, but for the four dominant seasons.

processes over Hyderabad are discussed for the entire data set for the period April 2009-March 2010 (Fig. 3), on seasonal basis (Fig. 4) and a summary in Fig. 5.

Several key features are obvious from Fig. 3. There is a large scatter in the low AOD aerosols with negative curvature, which are mostly confined to large fraction of fine-mode particles changing from $30 \%$ to $90 \%$ on occasion. The data scatter shows that high AOD values are mainly clustering at the fine mode associated with large $\alpha>1.0$, negative $d \alpha$ and large $\eta>70 \%$ values. This feature is characteristic for polluted urban environments as similar results were observed over Beijing and Kanpur (Gobbi et al., 2007). However, we notice several cases associated with low $\alpha<0.8$ and few cases where high AODs are associated with low $\alpha<0.4$ and $\eta<50 \%$ values suggesting the presence of coarse-mode particles. It is seen that some of the data point at low AOD values do fall outside the classification scheme with $\eta$ value $>99 \%$, and these may be associated with larger errors in $\alpha, d \alpha$ estimation. The data shown in Fig. 3 also suggest that changes in AOD are mostly associated with the concentration of finemode particles. For better understanding the aerosol optical properties, types and modification processes during different synoptic meteorological conditions observed during the year, we have plotted the data on seasonal basis and are shown in Fig. 3. These figures show unmistakable differences regard- ing the aerosol types and their modification processes during the four different climate periods over Hyderabad.

\subsubsection{Winter}

The data shown in Fig. 4a for the winter period clearly reveals the lowest variability among all seasons and indicates a well-mixed aerosol type and homogeneous atmosphere over urban Hyderabad. The large values of $\alpha$ (1.1-1.5), the large negative $d \alpha$ (below -0.4 in most cases) and the $\eta$ values $>70 \%$ suggest the dominance of fine-mode aerosols from local anthropogenic origin, i.e. fossil-fuel combustion, manure burning, open fires, etc. It is seen that an increase in AOD does not seem to affect significantly the prevailing aerosol features. Nearly the entire data points lie between 0.15 and $0.20 \mu \mathrm{m}$ of the $R_{\mathrm{f}}$ lines, even for the most turbid atmospheres $(0.6<\mathrm{AOD}<0.8)$. As stated above some of the data points, corresponding to the transparent conditions having $\alpha \sim 1.0-1.2$ and large negative $d \alpha(\sim-0.8)$, lie outside the classification scheme boundary, which is caused by large error in $\alpha$ and $d \alpha$ estimates or due to higher refractive index (i.e. larger than 1.4-0.001i assumed for the grid lines). It is to be noted that the grid lines in the classification scheme depend on the assumed value of refractive index and, therefore, an assessment of modal radii $R_{\mathrm{f}}$ is qualitative 
and one to be used to evaluate the relative size displacements (G. P. Gobbi, personal communication). Few data points having $\mathrm{d} \alpha \sim 0$ and $\eta<50 \%$ in the Fig. 4a, suggest the influence of transported dust over the region from a west-northwestern directions which can also occur in winter, although only occasionally (Badarinath et al., 2010).

\subsubsection{Pre-monsoon}

As can been seen from Fig. $4 \mathrm{~b}$, the pre-monsoon data $(\alpha$, $d \alpha$ and AOD) exhibits the largest variety in values suggesting diversity in the dominant aerosol types and a mixture of both fine and coarse-mode particles. A pronounced difference between pre-monsoon and the other seasons is the presence ( $\sim 10 \%$ ) of positive $d \alpha$ values. These values correspond to high AODs $(>0.6)$ in the vast majority of the cases suggesting an enhanced presence of coarse-mode aerosols $(\eta<60 \%)$ in turbid atmospheres. On the other hand, the majority of the data points lie close to the $R_{\mathrm{f}}=0.15 \mu \mathrm{m}$ line having larger values of $\eta(>70 \%)$ as the AOD increases, revealing abundance of freshly emitted fine particles and it is likely the result of secondary aerosol formation through gasto-particle conversion due to increased solar radiation. These also lead to increased AOD values in late pre-monsoon season, which is also seen by the large $\alpha(1.3-1.6)$ and the negative $d \alpha$ values during that periods. The data clearly demonstrate that majority of the aerosols in the turbid atmospheres are fine-mode, mainly caused by local anthropogenic pollution or biomass burning, since forest fires are also more frequent in this season due to hot and dry atmospheric conditions apart from the agricultural burning. Furthermore, contractually for nearly all the cases with $\mathrm{AOD}<0.4$, the $\alpha$ values are much lower $(<0.8)$ but with negative $d \alpha$ and $R_{\mathrm{f}}>0.2 \mu \mathrm{m}$. These cases correspond to aerosol size distribution with a pronounced coarse dominance and can be attributed to the presence of mineral dust particles or resuspended dust within the dry urban environment. Being located in south-central India and far away from the major dust source regions of Middle East, Arabia and Thar desert, the environment over Hyderabad is not so strongly affected by the dust as it was observed over northern India (El-Askary et al., 2006; Prasad and Singh, 2007a; Gautam et al., 2009b). These measurements also show cases of zero or even positive $d \alpha$ values (Fig. 4b), which correspond to bimodal size distributions with considerable coarse contribution, and these occur for larger AOD values and large $\alpha$ suggesting a mixing of natural and anthropogenic aerosols (Eck et al., 2005).

\subsubsection{Monsoon}

Indian summer monsoon, due to its typical meteorological and climatic characteristics, strongly affects the aerosol load and properties over Peninsular India (e.g. Prasad and Singh, 2007b; Gautam et al., 2009a). The $\alpha$ vs. $d \alpha$ plot during monsoon (Fig. 4c) strongly differs from those obtained during other seasons with the main difference being a shift towards the lower $\alpha(<1.0)$ values and $\eta(<70 \%)$; thereby suggesting a dominance of aerosols of coarse mode. The cases having $\mathrm{AOD}<0.2$ are associated with negative $d \alpha$ values and may correspond to cases with dilution of the large particles after rain washout. It is to be noted that for these cases, the $\eta$ values are above $70 \%$, while they lie near to $R_{\mathrm{f}}=0.25 \mu \mathrm{m}$. This $R_{\mathrm{f}}$ value is larger than those found in winter and postmonsoon, suggesting water uptake and increase in size of the water-soluble urban aerosols due to humidification processes (see Gobbi et al., 2007) as the RH over Hyderabad is usually above $75 \%$. Such aerosol particles are composed of a large fraction of nitrates and sulfates, which are strongly hygroscopic in nature (Ferrare et al., 2000). The increasing AOD results in a shift towards zero $\mathrm{d} \alpha$ and lower $\eta$ values. On the other hand, $\alpha$ values are much more sensitive to the changes in $R_{\mathrm{f}}$ (Reid et al., 1999; Schuster et al., 2006); therefore, for AOD $>0.6$, the $R_{\mathrm{f}}$ values are close to $0.3 \mu \mathrm{m}$ and $\alpha<0.4$ indicates significant dust presence over the region. We can therefore conclude that the turbid atmospheres over Hyderabad in monsoon are related to sea-salt and dust occurrence, which is also seen in air mass trajectory analysis discussed later (see Fig. 9c). Kaskaoutis et al. (2009) have reported unique episodes of aerosol type associated with very high AOD $(\sim 1.0)$ and very low $\alpha(\sim 0.2)$ values during the summer monsoon over Hyderabad.

\subsubsection{Post-monsoon}

The changing air masses from northern directions in postmonsoon have a direct influence on the aerosol optical properties, which approach those observed in winter. Similar to winter and the monsoon, the low AOD cases show large negative $d \alpha$ values associated with a wide range of $\alpha(0.7-$ 1.4). The data presented in Fig. 4d, reveal that for increasing AOD, the data points exhibit larger $\alpha$ values without significant variation in $\eta$. The increase in $\alpha$ is closely associated with decrease in $R_{\mathrm{f}}$ to about $0.15 \mu \mathrm{m}$. This clearly suggests an enhanced presence of fine-mode aerosols, either freshly emitted locally or transported from northern India. The kharif crop residue burning in northern India and the northerly winds usually spread the biomass-burning aerosols over central and south India in the post-monsoon season (Badarinath et al., 2009). In fact, in northern and western parts of India, where rainfall is high and winter temperature is fairly low, only one crop of rice is grown during the month from June to November. The study of the size and mass distribution of particulate matter due to crop residue burning in northern India shows that the fine particulate matter $\left(\mathrm{PM}_{2.5}\right)$ contributed almost $55 \%$ to $64 \%$ to the respirable suspended particulate matter (RSPM), and its aerosol load of $\mathrm{PM}_{2.5}$, increases by about $80 \%$ during the rice crop residue burning compared to the wheat crop residue burning (Awasthi et al., 2011). Even though during the post-monsoon season, the atmospheric conditions are somewhat similar to those 


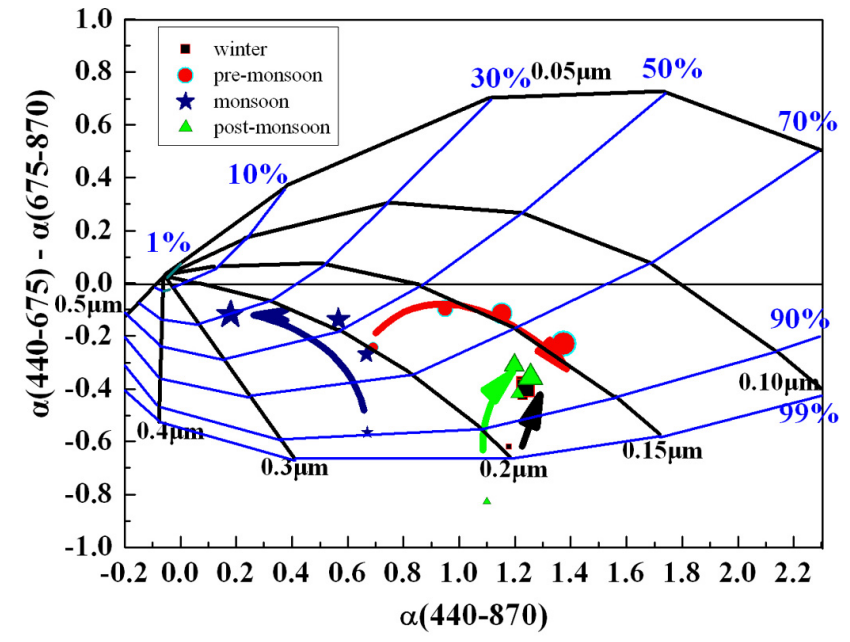

Fig. 5. Same as in Fig. 3, but using the seasonal mean $\alpha$ and $d \alpha$ values for each AOD group (i.e. AOD values from $<0.2$ to $>1$ ). The size of the symbols denotes the AOD group for each season. The size of each symbol corresponds to the AOD value; the larger the size the higher the $\mathrm{AOD}_{500}$.

observed in pre-monsoon and winter due to larger contribution of the fine-mode aerosols under turbid atmospheres, there is much lower contribution of transported dust compared to pre-monsoon. Thus, there are only few cases associated with low $\alpha$ and $\eta$ values and $d \alpha$ close to zero. On the other hand, in contrast to winter, a slight marine and dust influence still exists in post-monsoon, which is revealed from the tail of data points towards the origin in Fig. $4 \mathrm{~d}$.

\subsubsection{Seasonal average characteristics}

As seen in the Fig. 4, even though several conclusions regarding the aerosol characteristics over Hyderabad are apparent, a large scatter in the data does lead to visual uncertainties. Therefore, for each AOD group as shown in Fig. 4, we have computed the seasonal mean $\alpha$ and $d \alpha$ values along with the standard deviations given in Table 1 . The data in the table show a large seasonal change in the mean values as well as across the AOD range except during the winter season, where the data show the most homogeneous atmosphere since the variation of $\alpha$ and $d \alpha$ for increasing AOD is negligible. In the Fig. 5, we have plotted the seasonal mean $\alpha$ and $d \alpha$ values for each AOD group in order to better delineate the aerosol modifications with increasing AOD. The size of each symbol corresponds to the AOD value; the larger the size the higher the $\mathrm{AOD}_{500}$. Such large differences in the aerosol field highlight the strong influence of the local and regional meteorology in atmospheric dynamics and aerosols. During winter season for the AOD $<0.2$ group, the seasonal mean value of $R_{\mathrm{f}}=0.2 \mu \mathrm{m}$ associated with absolute dominance of fine particles $(\eta \sim 99 \%, \alpha=1.2$ and $d \alpha=-0.6)$. Increasing AOD leads to increase in $\alpha$, but with a slight decrease in $d \alpha, \eta$ and $R_{\mathrm{f}}$. The decrease in $R_{\mathrm{f}}$, although being very small, indicates freshly emitted soot aerosols, which can be verified by the higher $\mathrm{BC}$ concentrations in winter over Hyderabad and the whole of India (e.g. Beegum et al., 2009). On the other hand, increase in AOD causes decrease in both $\eta$ and $d \alpha$ suggesting an increase in coarse-mode volume fraction. Reid et al. (1999) also suggested that the coagulation process is more favorable under high turbid conditions and the larger aerosols are more efficient scatters. According to this, there is larger possibility for coagulation and condensation processes resulting in increase of the coarse-mode fraction.

In pre-monsoon the atmospheric condition is strongly changed with increased $\eta, \alpha$ and more negative $d \alpha$ values as AOD increases (except for AOD $<0.2$ ). The seasonal mean $\alpha$ vs. $d \alpha$ relationship shows a shift towards fine-mode particles along the steady $R_{\mathrm{f}}=0.15 \mu \mathrm{m}$. This suggests an increase in the volume fraction of fine particles, without considerable shift in the $R_{\mathrm{f}}$. During monsoon the atmospheric situation further changes with a clear dominance of coarse-mode particles. With an increase in AOD, the data points present a clear shift towards the origin along a nearly constant $R_{\mathrm{f}}$ of $0.2 \mu \mathrm{m}$. The fine-mode fraction shows a dramatic decrease from $90 \%$ for $\mathrm{AOD}<0.2$ to $30 \%$ for AOD $>0.6$. According to Gobbi et al. (2007) a shift of the data points towards the origin shows cloud contamination. Since our measurements were taken under clear skies the hydration process seems to be more active. Furthermore, the shift towards lower values of $\alpha$ and $\eta$ for increasing AOD may be an evidence of dust influence, as has been observed in Beijing and Kanpur (Gobbi et al., 2007) and in north African locations (Basart et al., 2009). A shift of data points towards lower $\alpha$ and $\eta$ values was also observed over far AS (Kaskaoutis et al., 2010) for distances $>400 \mathrm{~km}$ from the Indian coast where the anthropogenic influence is not so prominent. The similar results over urban Hyderabad in the monsoon highlight the influence of marine air masses also carrying dust aerosols from the west.

As seen in Fig. 4, the aerosol characteristics and the modification processes during post-monsoon season are similar to those found in winter. The main difference between them is the long tail towards the origin along a nearly constant $R_{\mathrm{f}}$ of $\sim 0.18 \mu \mathrm{m}$ associated with large AODs for post-monsoon season. For the aerosol group $(0.6<$ AOD < 0.8$) 14$ out of 17 cases have similar values $(\alpha \sim 1.4, d \alpha \sim-0.4, \eta \sim 90 \%)$. However, two of them are far away from this group (see Fig. 4d) thus, affecting the mean $\alpha, d \alpha$ values. If these two cases are removed the aerosol modification for increasing AOD will be slightly modified (Table 1), having the same characteristics as in winter.

\subsection{Intercomparison study with the conventional techniques}

In the previous analysis we have applied the classification scheme for the study of the aerosol optical properties and modification processes in the atmosphere over Hyderabad. 
Table 1. Seasonal mean $\alpha$ and $d \alpha$ values for each AOD group.

\begin{tabular}{|c|c|c|c|c|c|c|c|c|}
\hline \multirow[b]{2}{*}{ AOD group } & \multicolumn{2}{|c|}{ Winter } & \multicolumn{2}{|c|}{ Pre-monsoon } & \multicolumn{2}{|c|}{ Monsoon } & \multicolumn{2}{|c|}{ Post-monsoon } \\
\hline & $\alpha$ & $d \alpha$ & $\alpha$ & $d \alpha$ & $\alpha$ & $d \alpha$ & $\alpha$ & $d \alpha$ \\
\hline $\mathrm{AOD}<0.2$ & $1.18 \pm 0.09$ & $-0.62 \pm 0.13$ & & & & & $1.10 \pm 0.16$ & $-0.83 \pm 0.27$ \\
\hline $0.2<\mathrm{AOD}<0.4$ & $1.23 \pm 0.12$ & $-0.42 \pm 0.15$ & $0.68 \pm 0.31$ & $-0.25 \pm 0.15$ & $0.67 \pm 0.18$ & $-0.56 \pm 0.31$ & $1.21 \pm 0.14$ & $-0.42 \pm 0.14$ \\
\hline $0.4<\mathrm{AOD}<0.6$ & $1.23 \pm 0.18$ & $-0.38 \pm 0.12$ & $0.95 \pm 0.23$ & $-0.09 \pm 0.17$ & $0.67 \pm 0.26$ & $-0.25 \pm 0.16$ & $1.19 \pm 0.22$ & $-0.31 \pm 0.19$ \\
\hline $0.6<\mathrm{AOD}<0.8$ & $1.24 \pm 0.12$ & $-0.40 \pm 0.11$ & $1.15 \pm 0.25$ & $-0.11 \pm 0.25$ & $0.57 \pm 0.29$ & $-0.14 \pm 0.08$ & $* 1.25 \pm 0.41$ & $-0.36 \pm 0.162$ \\
\hline $0.8<\mathrm{AOD}<1.0$ & & & $1.37 \pm 0.09$ & $-0.23 \pm 0.23$ & $0.18 \pm 0.15$ & $-0.12 \pm 0.06$ & & \\
\hline
\end{tabular}

* Removing two cases with low $\alpha, d \alpha$ values in post-monsoon the seasonal mean will be modified to $\alpha(440-870)=1.39 \pm 0.16 ; d \alpha=-0.41 \pm 0.07$.

It is worth comparing the present analysis with the conventionally used methods. Traditionally, the aerosol characteristics from the spectral radiance measurements of a MT-II have been determined using AOD- $\alpha$ scatter plot and the inversion technique to retrieve optical equivalent aerosol size distributions and refractive indices.

\subsubsection{AOD versus Ångström exponent}

In the Angström's formula, $\alpha$ and the turbidity coefficient $\beta$ are considered independent from the wavelength. However, it is well known that these two parameters $\alpha$ and $\beta$ are strongly dependent on the wavelength used for its determination. A different kind of information can be revealed from $\alpha$ determined at shorter and longer wavelengths $\left(\alpha_{\lambda}\right)$; thus, the value of $\alpha$ at shorter wavelengths is more sensitive in changes in the radius of fine aerosols, while $\alpha$ at longer wavelengths provides sufficient information about the fine-mode fraction (Reid et al., 1999; Schuster et al., 2006). Thus, the relationship between $\alpha$ at shorter (380-500 nm) and longer $(675-870 \mathrm{~nm})$ wavelengths with $\mathrm{AOD}_{500}$ for different seasons as shown in Fig. 6a-d, can give us concurrent information about the changes in $R_{\mathrm{f}}$ and $\eta$ with increasing $\mathrm{AOD}_{500}$. It is seen from the figure that the scatter plot for the winter period does not show any change for $\alpha_{675-870}$ values with increasing AOD while a slight decreasing trend is seen for the $\alpha_{380-500}$ data. This indicates a small increase in $R_{\mathrm{f}}$ accompanied with negligible variation in $\eta$ for increasing AOD. However, Fig. 5 (described in Sect. 4.2) shows that the increase in AOD causes a small decrease in $R_{\mathrm{f}}$ (from 0.2 to $0.17 \mu \mathrm{m}$ ) and a small decrease in $\eta$. The results seem to be contradictory but it can be seen that both techniques reveal negligible variation in $\alpha_{\lambda}, R_{\mathrm{f}}$ and $\eta$ with increasing AOD and are well within the uncertainties in the correlations (i.e. large scatter in Fig. 6a).

In pre-monsoon period the correlation behaviour is very different and both $\alpha(380-500)$ and $\alpha(675-870)$ increase with AOD, with the larger increase for $\alpha_{675-870}$, indicating a decrease in $R_{\mathrm{f}}$ and a pronounced increase in $\eta$. These results are in excellent agreement with those arrived from the classification scheme described in Fig. 5 for pre-monsoon season, which also shows a decrease in $R_{\mathrm{f}}$ value (from 0.2 to $\sim 0.15 \mu \mathrm{m}$ ) associated with a large increase in $\eta$ (from $\sim 55 \%$ to $\sim 75 \%$ ). It is worth noting that the lowest AOD group $(0.2<$ AOD < 0.4$)$, from Fig. $6 \mathrm{~b}$, does lead to the increasing trend in the $\alpha_{380-500}$; by excluding these values, the trend becomes neutral, leading to negligible variation in $R_{\mathrm{f}}$ as seen Fig. 5.

The scatter plot of $\alpha_{\lambda}$ with $\mathrm{AOD}_{500}$ in monsoon (Fig. 6c) is quite different, showing no variation for shorter wavelengths and a strong decreasing trend for the longer ones. The results are in close agreement with those arrived from classification scheme (Fig. 5) for monsoon season indicating a large decrease from $90 \%$ to $30 \%$ in $\eta$ and no variation in $R_{\mathrm{f}}$. Note also that the strong negative correlation between $\alpha_{675-870}$ and AOD in monsoon corresponds to the largest decrease in the fine-mode fraction and the similar result can also be seen from Fig. 5. In the case of post-monsoon period (Fig. 6d), the characteristics of the $\alpha(380-500)$ and $\alpha(675-870)$ are similar to that seen in the classification scheme analysis (Fig. 5). The increase in AOD causes a slight decrease in $\alpha_{675-870}$ (Fig. 6d) and in $\eta$ (Fig. 5). However, the only notable inconsistency between the two methods during this period is for $\alpha_{380-500}$ values, since Fig. 6d shows a decreasing trend of this parameter with AOD, while the data in the Fig. 5 suggests a decrease in $R_{\mathrm{f}}$. This may be attributed to uncertainties for the data points having AOD $<0.2$ (some of the seasonal mean data point lie outside from the classification scheme in Fig. 5). Removing these data from both figures, the variation of $R_{\mathrm{f}}$ becomes negligible as from Fig. 5 and the regression line of $\alpha_{380-500}$ in the Fig. 6d tends to be neutral.

From the comparison of the results obtained using two different methods as discussed above, a fair degree of consistency between the two is shown, even though data used in Figs. 4 and 5 correspond to different parameters and different spectral bands.

\subsubsection{Aerosol columnar size distribution}

The aerosol size distribution is a crucial parameter for accurate assessment of radiative forcing. As described in Sect. 3, the CSDs for each AOD group during different seasons were retrieved by inverting the seasonal mean spectral AODs using King's algorithm. The CSDs were parameterized using several model fits until the fitted size distribution agreed well with the retrieved one. Log-normal distributions with two 

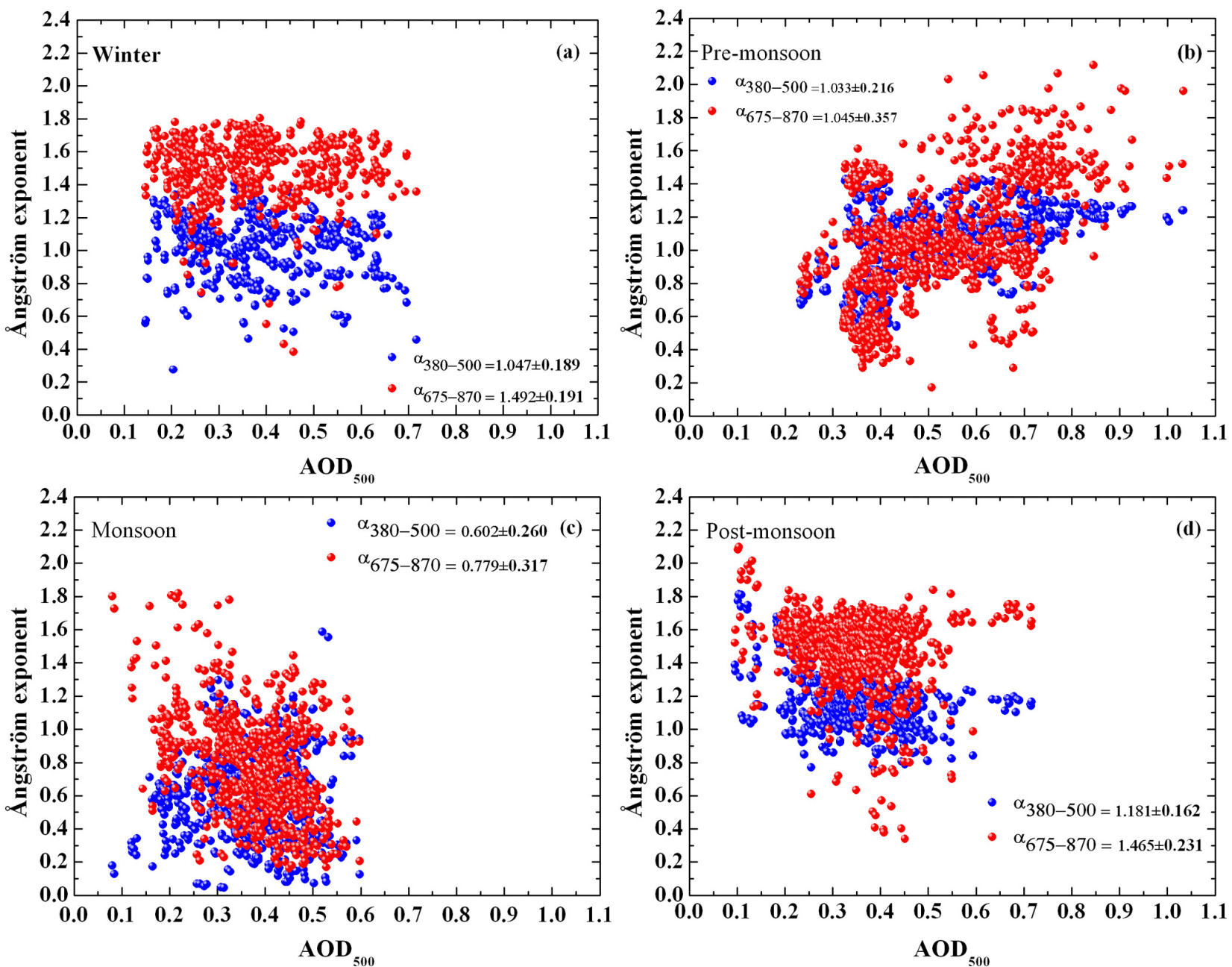

Fig. 6. The $\mathrm{AOD}_{500}$ versus Ångström exponent $(\alpha)$ at shorter (380-500) and longer (675-870) wavelengths for each season over Hyderabad during the period April 2009-March 2010. The $\alpha$ at shorter wavelengths is more sensitive in changes in the radius of fine aerosols $\left(R_{\mathrm{f}}\right)$, while $\alpha$ at longer wavelengths provides concurrent information about the fine-mode fraction $(\eta)$ with increasing $\operatorname{AOD}_{500}$.

modes namely, bimodal given by Eq. (7), a unimodal (UM), power law (PL) and/or a combination of PL for fine mode and UM for coarse mode distributions shown as Eq. (8) were used for the retrievals.

$n(r)=\sum_{i=1}^{2} \frac{N_{0 i}}{\sqrt{2 \pi} \sigma_{i} r} \exp \left[-\frac{\left(\ln r-\ln r_{m i}\right)^{2}}{2 \sigma_{i}^{2}}\right]$

$n(r)=N_{01} r^{-v}+\frac{N_{02}}{\sqrt{2 \pi} \sigma_{2} r} \exp \left[-\frac{\left(\ln r-\ln r_{m 2}\right)^{2}}{2 \sigma_{2}^{2}}\right]$

where $N_{0 i}$ is the columnar aerosol number concentration, $r_{m i}$ and $\sigma_{i}$ are the mode radius and the standard deviation of the mode radius, respectively, while $i=1$ represents the fine and $i=2$ the coarse mode. $v$ is the power law index (aerosol size index), varying from $\sim 2$ to $\sim 5$ for ambient aerosol distribution and is highly sensitive to biomass-burning and an- thropogenic aerosols; a large value of $v$ indicates the dominance of sub-micron particles (Nair et al., 2008). The values of the best fit parameters for each AOD group corresponding to different season are summarized in Table 2 . The retrievals are plotted in Fig. 7. The left panels in the figure show the measured spectral AODs and the reestimated values from the retrieved CSDs, while the right panels give the retrieved CSDs during the present analysis. It is seen from the figure that for all the seasons and AOD groups, the agreement between measured and estimated spectral AODs is satisfactory thereby allowing an accurate retrieval of the CSDs. An intercomparison of the data plotted in Fig. 7 clearly shows that the simulated fits strongly differ among the AOD groups and depend on the season. Properties of the columnar size distributions retrieved from the present data during different seasons are discussed in the following section. 
Table 2. Statistical parameters of the fitted simulation curves in CSDs for each season and AOD group. [UM: unimodal, PL: power law, PL + UM: combination of power law and unimodal, BM: bimodal].

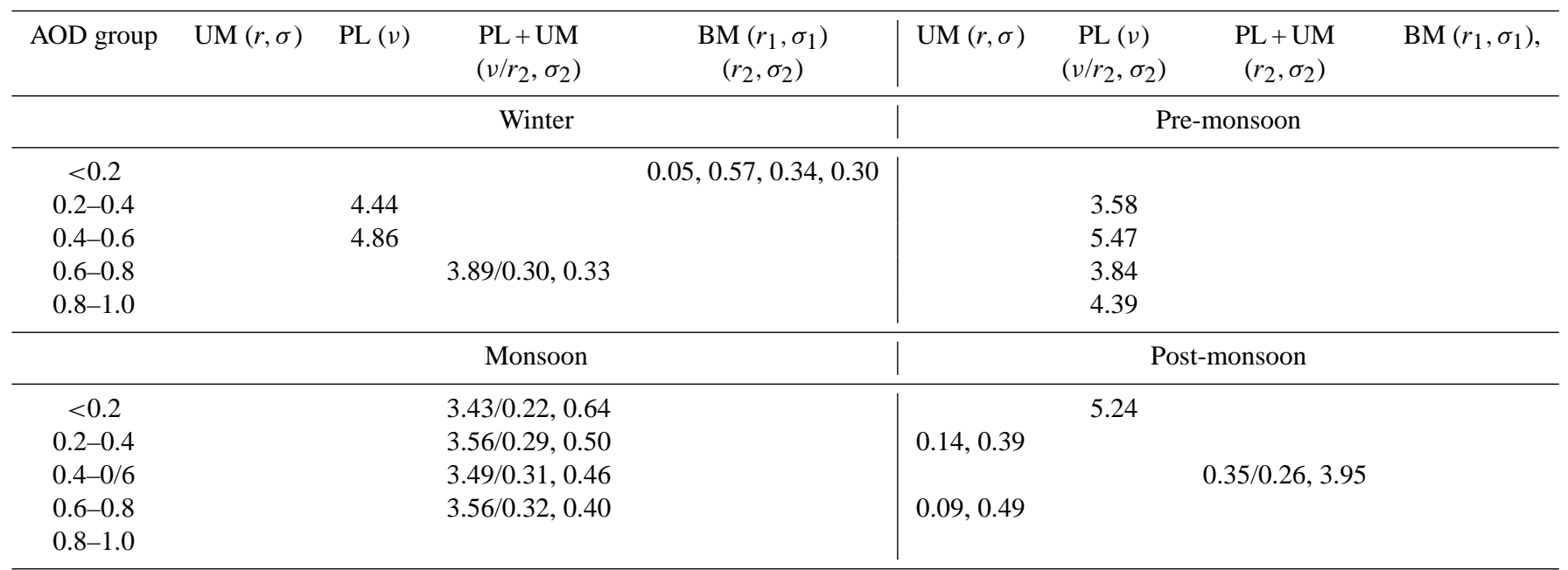
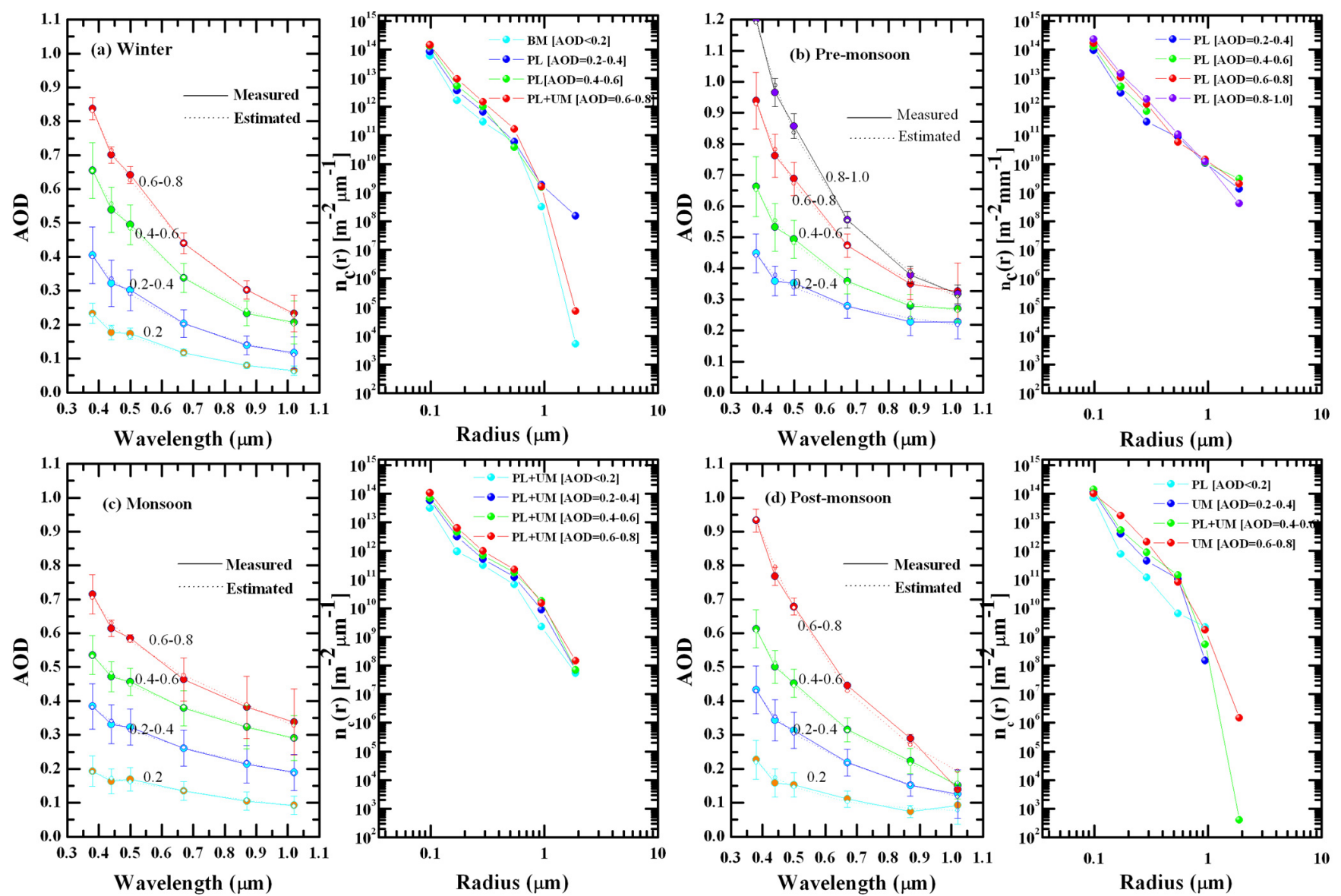

Fig. 7. Mean-aerosol columnar size distribution (right panels) for each AOD group retrieved from the inversion of Eq. (1) for each season over Hyderabad. The measured and reestimated spectral AODs used for the columnar size distribution retrievals are shown in left panels.

\section{Winter}

During winter, the lowest AODs in winter are best fitted by a bimodal distribution with two distinct modes for sub- micron particles, i.e. nucleation mode $\left(r_{1}=0.05, \sigma_{1}=0.57\right)$ and $\left(r_{1}=0.34, \sigma_{1}=0.30\right)$ for the accumulation mode (see 
Fig. 7a). These mode radii are much lower than those found for fine-mode aerosols over coastal India $(r=0.15)$, tropical Indian Ocean $(r=0.12)$ and AS $(r=0.10)$ region (Ramachandran and Jayaraman, 2002) and are comparable to those reported for nucleation mode and accumulation mode, respectively, over BoB (Ganguly et al., 2005). The large $v$ values (4.44 and 4.86) for the PL distributions and the $r_{2}=0.30 \mu \mathrm{m}$ for the PL + UM distribution (Table 2), suggest the large abundance of fine particles in winter over the urban environment, consistent with the increased biomass burning. The increase in AOD causes a pronounced increase in $n_{\mathrm{c}}$ for the fine and accumulation-mode aerosols $(0.1<r<0.6)$, while lower concentrations are found for the coarse-particles $(r>1 \mu \mathrm{m})$ under turbid atmospheres.

\section{Pre-monsoon}

During pre-monsoon all CSDs are best represented by PL distribution (i.e. Junge distribution) with large $v$ values (3.58-5.47) in general (Fig. 7b). These values are larger than even those found over AS (3.8 to 4.2) in pre-monsoon season during the ICARB experiment (Nair et al., 2008). The changes in values of CSDs parameters for increasing AOD suggests a shift towards higher concentration of fine and accumulation-mode particles similar to those concluded in Figs. 4 and 5. For the several cases dominated by coarsemode aerosols, they have no clear signal in the mean CSDs, and increase in AOD associated with increase in fine-mode particles. This may be caused by the mixing of natural and anthropogenic aerosols within the urban environment. It is to be noted that even though aerosol distribution is governed by the power law, the $n_{\mathrm{c}}$ values for the coarse aerosols are much larger in the pre-monsoon season compared to the other seasons.

\section{Monsoon}

In the monsoon season all the CSDs are better parameterized with a combination of PL and UM distributions (Fig. 7c). A comparison between various AOD groups does not show any clear trend in the value of $v$ with the increasing AOD (Table 2). However, the increased AOD does affect $r_{2}$, for which the values increased from $0.22 \mu \mathrm{m}$ to $0.32 \mu \mathrm{m}$ along with a progressive reduction in the width of the distribution $\sigma_{2}$ as seen in Table 2. This indicates a shift of the CSDs towards larger radius for the coarse-mode aerosol. Such a feature is characteristic for the mixture with considerable influence of dust particles (Duchi et al., 2011). Furthermore, for increasing AOD the CSDs present a shift towards larger $n_{\mathrm{c}}$ affecting slightly more the coarse modes. This agrees with the decrease in $\alpha, d \alpha$ and $\eta$ values observed in monsoon season (see Fig. 5, Table 1). On the other hand, the aerosol optical properties depend on size, shape and chemical composition of the particles, as well as on ambient RH. Because of their hygroscopic nature these aerosols are very sensitive in wa- ter uptake resulting in size enlargement, increase in $R_{\mathrm{f}}$ and reduction in $\alpha$.

\section{Post-monsoon}

During post-monsoon season, the CSDs show a wide variety depending on the AOD value (Fig. 7d). For the lowest AOD group $<0.2$, the distribution is best parameterized with a PL with a steep power-law index $v=5.24$. This large value indicates considerable presence of soot aerosols as it was seen in the winter and pre-monsoon seasons (Table 2). However, this value is associated with a larger degree of measurement uncertainty, as discussed earlier. For the higher AOD group of 0.2-0.4, the distribution becomes UM with $r=0.14$ and $\sigma=0.39$. For the AOD group of 0.4-0.6, the best fit corresponds to a PL with $v$ value of 0.35 and a UM component with $r_{2}=0.26$ and $\sigma_{2}=3.95$. With the further increase in AOD, the CSD once again becomes UM with $r=0.09$ and $\sigma=0.49$. It is seen in Fig. 7 that $n_{\mathrm{c}}$ in the size range $\sim 0.15-0.7 \mu \mathrm{m}$ increases significantly with the increasing AOD, thereby suggesting additional presence of fineand accumulation-mode aerosols, similar to the results from Figs. 4 and 5. It is to be noted that the low concentrations of coarse-mode particles for high AOD is similar to that found during the winter season. The observed lower $r$ value $\sim 0.09$ for the highest AOD group is also confirmed from the classification scheme for this season (Fig. 5).

\section{Derived parameter}

The derived parameters namely effective radius $\left(R_{\text {eff }}\right)$, mass loading $\left(M_{\mathrm{L}}\right)$, total $\left(N_{\mathrm{T}}\right)$, submicron $\left(N_{\mathrm{a}}\right)$ and supermicron $\left(N_{\mathrm{c}}\right)$ and the ratio $\left(N_{\mathrm{c}} / N_{\mathrm{a}}\right)$ from CSD is shown in Fig. 8a$\mathrm{d}$ for the different seasons and AOD groups same as presented in Figs. 3 and 4. All the aerosol size derived parameters showed the large seasonal variation indicating the influence of the changes in synoptic meteorology affecting the aerosol distribution. The variation of $R_{\text {eff }}$ is relatively featureless except for post-monsoon season which show the increasing $R_{\text {eff }}$ with increasing AOD. Moreover, the significant seasonal variation in $R_{\text {eff }}$ being higher value during monsoon and pre-monsoon and lower in winter and post-monsoon seasons for the same AOD group suggest the large sensitivity of $R_{\text {eff }}$ with the coarse mode fraction. As expected, the other parameters namely $M_{\mathrm{L}}, N_{\mathrm{T}}, N_{\mathrm{a}}$, and $N_{\mathrm{c}}$ showed the increasing trend with increasing AOD for all the season except post-monsoon which showed the lower values for the higher AOD. The detailed comparison study between the results arrived from aerosol size derived parameters and classification scheme (discussed earlier) is presented in the following section. 

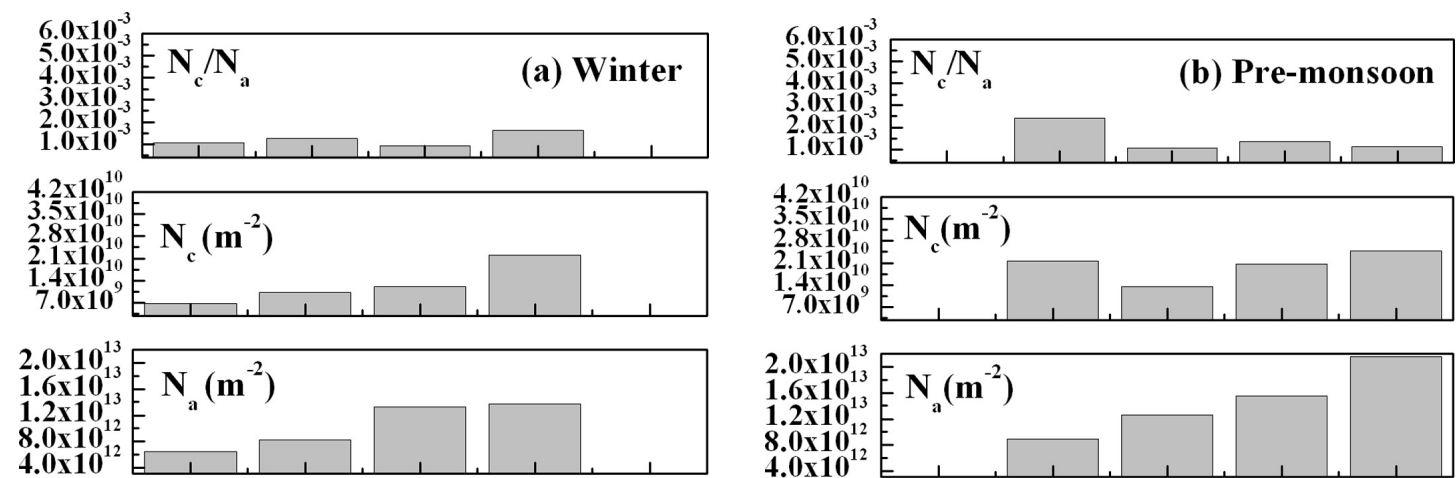

$4.0 \times 10$
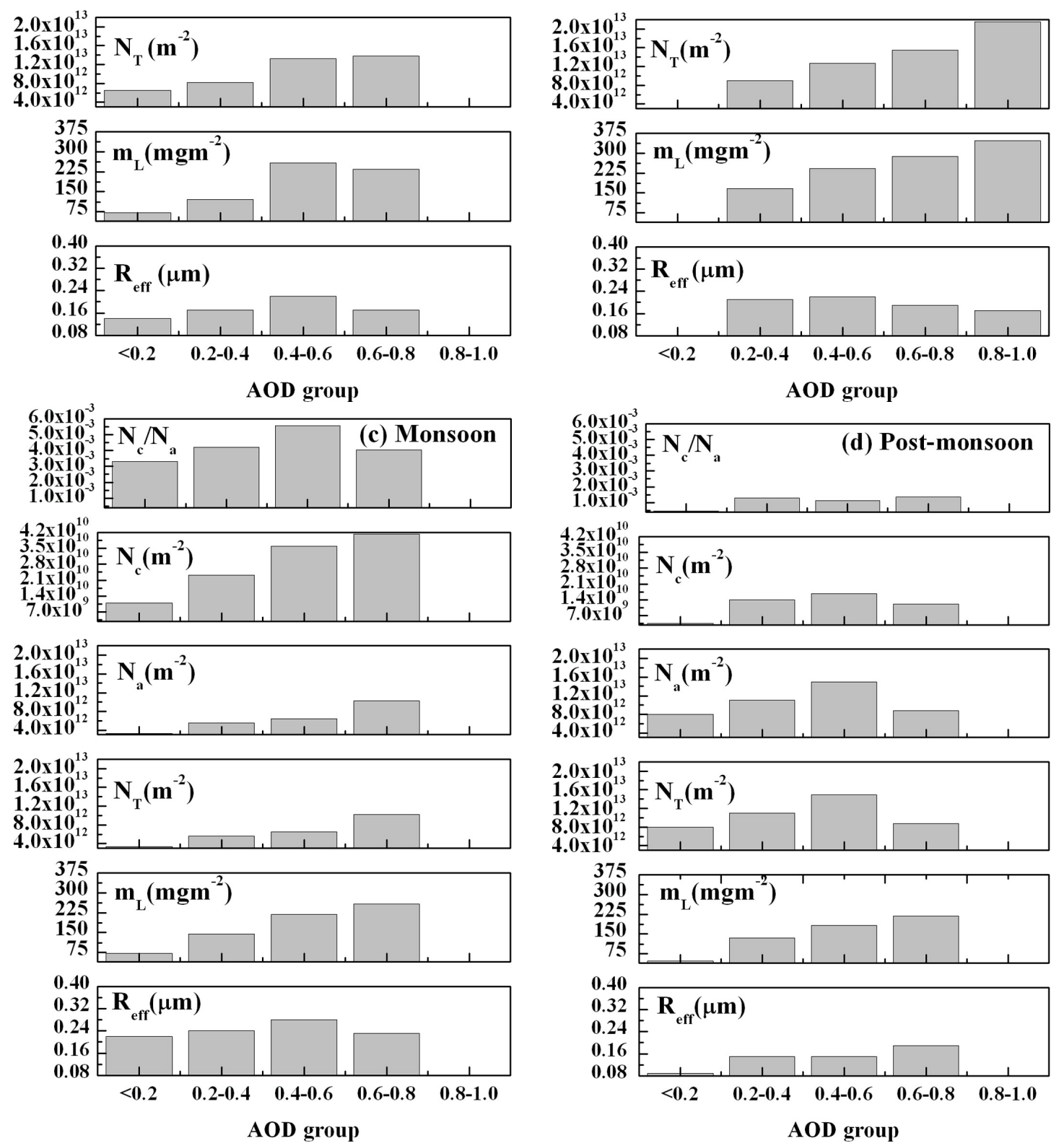

Fig. 8. Variation of the retrieved parameters $R_{\mathrm{eff}}\left(m_{\mathrm{L}}, N_{\mathrm{T}}, N_{\mathrm{a}}, N_{\mathrm{c}}\right.$, and $\left.N_{\mathrm{c}} / N_{\mathrm{a}}\right)$ from the columnar size distributions on a seasonal basis for the different AOD groups over Hyderabad. 
Comparison of the retrieved parameters from the CSDs and the classification scheme

The retrieved parameters from the CSD analysis are plotted in Fig. 8 for each season and AOD group. A comparison of different parameters across the AOD ranges during different seasons is quite instructive. The clear differences are also seen in the relative trends during different seasons. In an effort to establish a relative measure of aerosol properties using CSDs and classification scheme techniques, the comparative characteristic of the derived parameters $R_{\mathrm{f}}, \eta$ from the classification scheme with the corresponding ones $R_{\mathrm{eff}}, N_{\mathrm{c}} / N_{\mathrm{a}}$ retrieved from the CSD analysis are discussed. It should be noted that such a comparison is only qualitative in nature and not quantitative. Even though in both the cases, the parameters represent similar quantities, i.e. size and fine-mode fraction, the definitions for the two sets are quite different. For example, the $R_{\mathrm{f}}$ corresponds to the modal radius of the finemode particles, while $R_{\text {eff }}$ is the effective radius of the composite aerosol loading.

From the comparison between the two sets of characteristic variables, we note that during the winter period the $R_{\text {eff }}$ changes non-linearly, i.e. increases initially and then decreases (Fig. 8a). This is consistent with the slight variation in $R_{\mathrm{f}}$ seen in the results from Fig. 5. The $R_{\mathrm{eff}}$ value of $\sim 0.17$ for the 2nd and 4th AOD group is similar to the $R_{\mathrm{f}}$ of the respective AOD groups in Fig. 5. As seen in Fig. 8a, all parameters related to aerosol load $\left(m_{\mathrm{L}}, N_{\mathrm{T}}, N_{\mathrm{a}}, N_{\mathrm{c}}\right)$ increase with increasing AOD, while no pronounced variation is shown for the $N_{\mathrm{c}} / N_{\mathrm{a}}$ ratio; except for a slight increase, which is in accordance with the slight decrease in $\eta$ value shown in Fig. 5. In the pre-monsoon season (Fig. 8b), the slight decrease in $R_{\text {eff }}$ and $N_{\mathrm{c}} / N_{\mathrm{a}}$ with increasing AOD is in general agreement with the variation in $R_{\mathrm{f}}$ and $\eta$, respectively, suggesting lower particle size and increased fine-mode fraction; however, the variation in $N_{\mathrm{c}} / N_{\mathrm{a}}$ is not as intense as that in $\eta$.

During monsoon period (Fig. 8c), the aerosol load increases significantly for increasing AOD, mainly made up of coarse particles, while the $R_{\text {eff }}$ and the $N_{\mathrm{c}} / N_{\mathrm{a}}$ exhibit their largest values. The effect of the coarse-mode aerosols is clearly detected in both the CSD and the classification scheme. The $R_{\mathrm{f}}$ values of $\sim 0.20-0.27$ (Fig. 5) and its slight variation are similar to those found for $R_{\text {eff }}$. A small inconsistency in terms of slight decrease of the $N_{\mathrm{c}} / N_{\mathrm{a}}$ for the largest AOD group is seen in the data. However, the increase in $N_{\mathrm{c}} / N_{\mathrm{a}}$ ratio during monsoon is larger than those found in the other seasons and is in absolute agreement with the results of Fig. 5, which show the large variation in $\eta$ from $30 \%$ to $90 \%$. It is also observed the pronounced decreasing trend in $\alpha_{675-870}$, shown in Fig. 8c. During post-monsoon (Fig. 8d), the $R_{\text {eff }}$ exhibits a considerable increase for the highest AOD group, without such evidence in $R_{\mathrm{f}}$ (Fig. 5). It may be due to the changes in $R_{\text {eff }}$ for the cases corresponding to large coarse-mode aerosols. In general, the $N_{\mathrm{c}} / N_{\mathrm{a}}$ ratio remains very low without any large variation which agrees with the slight variation and the high values of $\eta$ (Fig. 5).

The inter comparison of the derived parameters from different techniques, i.e. the classification scheme, the CSDs and the relationship between AOD and $\alpha$, reveal a fair degree of consistency between them. Therefore, the classification scheme method can adequately describe the aerosol optical properties and modification processes in the atmosphere.

\subsection{Air mass trajectories and characteristics of aerosols}

The characteristic of aerosols is substantially modified by the synoptic-scale atmospheric transport patterns from different sources. In this regard, a 7-day isentropic air-mass backward trajectories cluster analysis was made for all the days of MT-II observations at 07:00 (UTC) using the Hybrid Single Particle Lagrangian Integrated Trajectory (HYSPLIT) model (Draxler and Rolph, 2003), to reveal the sources of aerosol types observed over Hyderabad. The backward air mass trajectory simulations are obtained by running the HYSPLIT model (http://ready.arl.noaa.gov/HYSPLIT.php). The cluster analysis is a multivariate statistical technique and it has additional advantages from the normal air trajectory because it simultaneously accounts for the variation in transport speed as well as the direction (Harris and Kahl, 1990). In this technique, each trajectory is considered as a cluster and the spatial variance (SPVAR) is calculated for every combination of trajectory pairs. SPVAR is defined as the sum of the squared distances between the endpoints of the cluster's component trajectories and the mean of the trajectories in the same cluster. In the next step, the total spatial variance (TSV)(the sum of all the cluster spatial variances) is calculated and those pair of clusters for which an increase in TSV is the lowest, are combined. Following the above procedure, the data were segregated for the four typical seasons and cluster mean trajectories and their percentage contributions were estimated at $1500 \mathrm{~m}$ above ground level as shown in Fig. 9a-d.

The results obtained from the classification scheme are further discussed in view of the air-mass trajectories cluster analysis. For each season, the trajectories were grouped into five main pathways by means of cluster analysis discussed above. The main pathways revealed from the cluster analysis are (1) air masses from Africa-Arabia-Middle East, (2) air masses from southern AS and North Indian Ocean (NIO), (3) air masses from Indo-Gangetic Plain, (4) air masses from Bay of Bengal and southeast Asia, (5) local air masses. The air mass pathways for each season are related to aerosols properties derived from MT-II (Table 3).

It is seen that during the winter period (Fig. 9a), the $72 \%$ of the air masses arrive from northern directions, where intense fog and pollution-haze conditions occur during this season (Gautam et al., 2007; Das et al., 2008). The lower altitude trajectories favor the transport of pollution aerosols over Hyderabad in winter. The $28 \%$ of observed air masses arriving from the west, $12 \%$ from the Middle East and $16 \%$ from the 

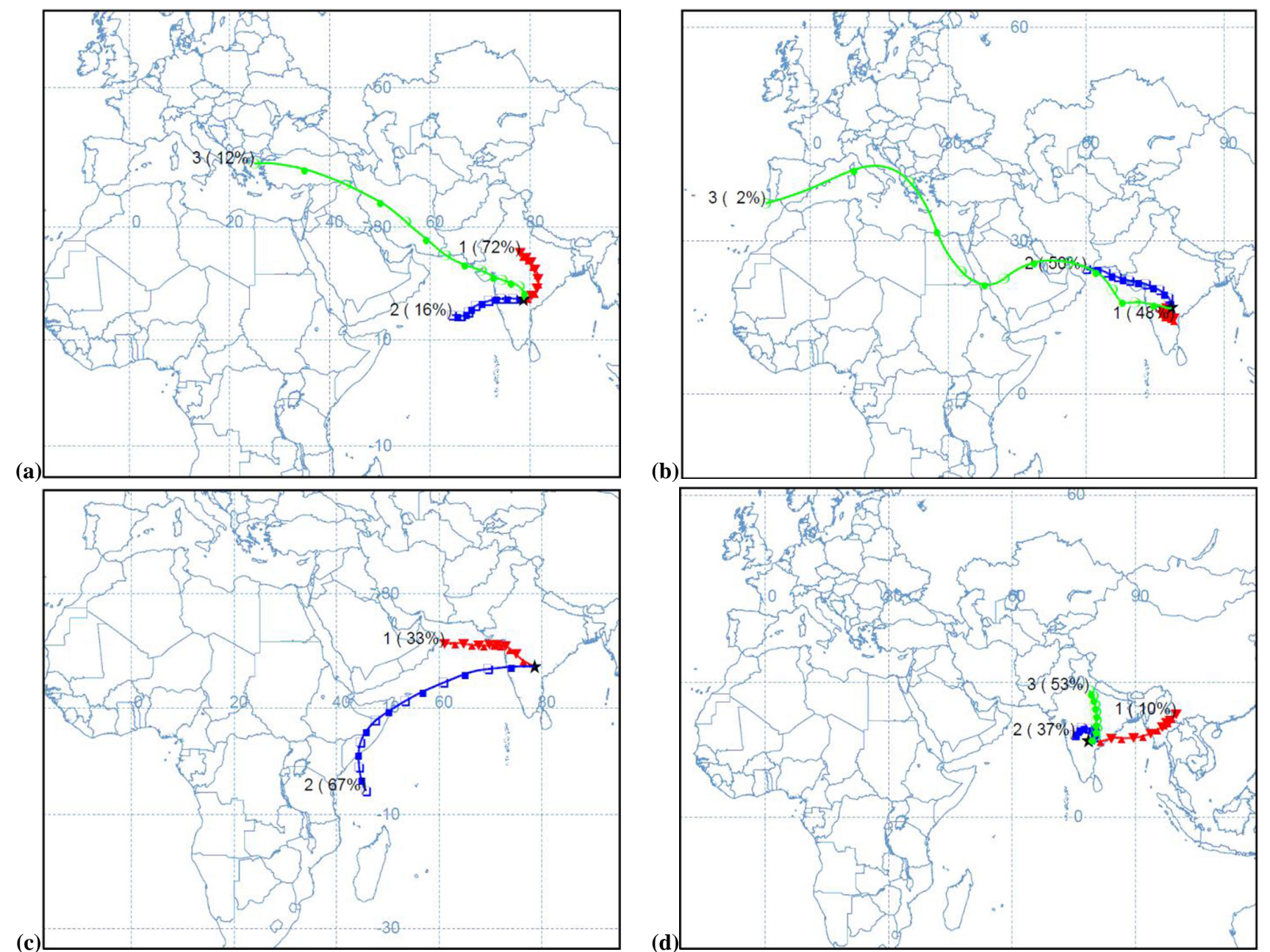

Fig. 9. Seasonal mean clusters for air mass back-trajectories arriving over Hyderabad at $1500 \mathrm{~m}$ for the days of Microtops-II observations during the period April 2009-March 2010. The percentage contribution of each cluster is also indicated. The air mass trajectories are obtained via HYSPLIT model (http://ready.arl.noaa.gov/HYSPLIT.php).

Table 3. Seasonal mean of various aerosol parameters over Hyderabad during the period April 2009-March 2010. [NI: North India, AS: Arabian Sea, AA: Africa-Arabia, AP: Arabian Peninsula, LC: Local Continental, SWAS: South-West Arabian Sea, IGP: Indo-Gangetic Plain, SEA: South-East Asia].

\begin{tabular}{lccccc}
\hline Season & Source region & AOD $_{500}$ & $\alpha(440-870)$ & $d \alpha$ & $\beta$ \\
\hline Winter & NI, AS, AA & $0.39 \pm 0.12$ & $1.41 \pm 0.15$ & $-0.41 \pm 0.16$ & $0.15 \pm 0.05$ \\
Pre-M & AP, LC, & $0.53 \pm 0.12$ & $1.11 \pm 0.23$ & $-0.17 \pm 0.18$ & $0.22 \pm 0.05$ \\
Monsoon & AP, SWAS & $0.37 \pm 0.11$ & $0.67 \pm 0.23$ & $-0.2 \pm 0.11$ & $0.25 \pm 0.1$ \\
Post-M & LC,IGP,SEA & $0.37 \pm 0.12$ & $1.26 \pm 0.27$ & $-0.4 \pm 0.19$ & $0.16 \pm 0.06$ \\
\hline
\end{tabular}

Arabian Sea, are driven by the western synoptic circulation pattern in northern mid-latitudes. Since these traverse the arid regions of Arabia and Iran, these air masses normally carry significant amounts of dust over the Arabian Sea and continental India on certain occasions (Badarinath et al., 2010). However, the low frequency (12\% and $16 \%)$ of occurrence of arid and marine air masses in winter do not favor considerable presence of coarse-mode particles and the CSD is domi- nated by fine-mode aerosols either produced locally or transported from northern India and it is in an excellent agreement with the aerosol types discussed in the previous sections for this season from different techniques (see Figs. 4a and 7a).

During pre-monsoon season (Fig. 9b), the $50 \%$ of the air masses arriving at Hyderabad originate from Arabian peninsula and Middle East and these are rich in coarse-mode aerosols as the dust activity over the region is at its maximum 
(Gautam et al., 2009b). On the other hand, in several cases $(48 \%)$ the air masses come from the Indian sub-continent itself and which usually carry aerosols from biomass-burning as a result of the crop residue burning during March-May period. This leads to enhanced aerosol loading composed of mixture of both fine and coarse particles. A large AOD mean value of $0.53 \pm 0.12$, and a large value of $\alpha=1.11 \pm 0.23$ during this season is also consistent with the mixed aerosol types.

During monsoon period (Fig. 9c), the air-circulation pattern is driven by the strong southwestern winds. Although the air trajectories are clearly southwesterly with $67 \%$ of the air masses having an oceanic origin, the remaining $33 \%$ that originate from west Asia carry dust aerosols at higher altitudes. Such an aerosol mix of air masses of marine and/or desert origin leads to lower value of $\alpha(0.67 \pm 0.23)$. In postmonsoon (Fig. 9d), the trajectory clusters exhibit low occurrence of air masses from Southeast Asia (10\%). The remaining $90 \%$ of the air masses are mainly originating from IGP $(53 \%)$ and Southwest India (37\%), which carry an abundant anthropogenic pollution and biomass-burning aerosols in certain cases. This contributes to the presence of fine-mode aerosols, high $\alpha$ values $(1.26 \pm 0.27)$ and conditions similar to the winter season except for additional contribution arriving from the Bay of Bengal. A summary of the aerosol types in different seasons along with seasonal mean optical parameters are listed in Table 3.

\section{Conclusions}

The present study focused on the classification of the aerosol types and modification processes in the atmosphere over Hyderabad, India, using sun-photometer data. One year continuous measurements were used to study the aerosol characteristics on a seasonal basis. The aerosol optical and physical properties are obtained using three techniques (i) $\alpha$ vs. AOD, (ii) $\alpha, d \alpha$ vs. AOD (classification scheme) and, (iii) CSD using the King's inversion algorithm on seasonal basis. The important findings and results obtained from this study are summarized in the following:

1. The analysis of the seasonal data suggests the presence of fine-mode aerosols under turbid atmospheres in winter and post-monsoon, the concurrent presence of fine and coarse aerosols in pre-monsoon and the significant influence of marine mixed with dust aerosols in monsoon.

2. The seasonal variation in the aerosols modification processes were inferred using the graphical visualisation scheme as well as columnar aerosol size distribution analysis. The results reveal a well mixed aerosol type associated with the coagulation and condensation of particles during winter and post-monsoon. During premonsoon season freshly emitted fine particles associ- ated with secondary aerosol formation through gas-toparticle conversion and hydration process are observed. The data suggest that humidification process lead to increased hygroscopic growth of water soluble particles mixed with dust aerosols during monsoon season.

3. Increasing of AOD did not led to large variation in aerosol characteristics during post-monsoon and winter seasons indicating more homogeneous atmospheres, while the most turbid conditions in pre-monsoon were associated with enhancement of fine-mode aerosol concentrations and fine-mode fraction. In contrast, increasing of AOD in monsoon is strongly associated with a dramatic increase in coarse-mode particles.

4. The results from the classification scheme were further compared and discussed with those revealed from the correlation between $\mathrm{AOD}_{500}$ and $\alpha$ at shorter and longer wavelengths, and the columnar size distributions obtained using the King's inversion algorithm, as well as with air-mass trajectory cluster analysis. The combination of the results clearly defined the usefulness of the classification scheme and highlights its advantages for the aerosol monitoring and study of seasonal variation of the aerosol modification processes in the atmosphere.

Acknowledgements. We are thankful to the staff members of the National Balloon Facility for their support and help in maintenance and operation of the Microtops-II instrument. Authors would also like to thank Gian Paolo Gobbi, Julian Kuhlmann, S. K. Das, S. Basart, D. Anand, and Mohammad Reza Gohardoust for their fruitful discussion on the results and valuable inputs. We acknowledge NOAA Air Resources Laboratory for providing the HYSPLIT transport and dispersion model (http://www.arl.noaa.gov/).

Topical Editor P. Drobinski thanks R. P. Singh and one anonymous referee for their help in evaluating this paper.

\section{References}

Awasthi A., Agarwal R., Mittal, S. K, Singh, N., Singh, K., and Gupta, P. K.: Study of size and mass distribution of particulate matter due to crop residue burning with seasonal variation in rural area of Punjab, India, J. Environ. Monit., 13, 1073-1081, 2011.

Babu, S. S., Moorthy, K. K., Manchanda, R. K., Sinha, P. R., Satheesh, S. K., Prasad Vajja, D., Srinivasan, S., and Arun Kumar, V. H.: Free tropospheric black carbon aerosol measurements using high altitude balloon: Do BC layers build "their own homes" up in the atmosphere?, Geophys. Res. Lett., 38, L08803, doi:10.1029/2011GL046654, 2012.

Badarinath, K. V. S., Kharol, S. K., and Sharma, A. R.: Long-range transport of aerosols from agriculture crop residue burning in Indo-Gangetic Plains - A study using LIDAR, ground measurements and satellite data, J. Atmos. Solar-Terr. Phys., 71, 112120, 2009. 
Badarinath, K. V. S., Shailesh Kumar Kharol, Kaskaoutis, D. G., Anu Rani Sharma, Ramaswamy, V., and Kambezidis, H. D.: Long range transport of dust aerosols over Arabian Sea and Indian region - A case study using satellite data and ground-based measurements, Global Planet. Change, 72, 164-181, 2010.

Basart, S., Pérez, C., Cuevas, E., Baldasano, J. M., and Gobbi, G. P.: Aerosol characterization in Northern Africa, Northeastern Atlantic, Mediterranean Basin and Middle East from direct-sun AERONET observations, Atmos. Chem. Phys., 9, 8265-8282, doi:10.5194/acp-9-8265-2009, 2009.

Beegum, S. N., Moorthy, K. K., Babu, S. S., Satheesh, S. K., Vinoj, V., Badarinath, K. V. S., Safai, P. D., Devara, P. C. S., Singh, S., Vinod, U., Dumka, C., and Pant, P.: Spatial distribution of aerosol black carbon over India during pre-monsoon season, Atmos. Environ., 43, 1071-1078, 2009.

Cachorro, V. E., Romero, P. M., Toledano, C., Cuevas, E., and de Frutos, A. M.: The fictitious diurnal cycle of aerosol optical depth: A new approach for "in situ" calibration and correction of AOD data series, Geophys. Res. Lett., 31, L12106, doi:10.1029/2004GL019651, 2004.

Chakravarty, K., Mukhopadhyay, P., and Taraphdar, S.: Cloud microphysical properties as revealed by the CAIPEEX and satellite observations and evaluation of a cloud system resolving model simulation of contrasting large scale environments, J. Atmos. Sol. Terr. Phys., 73, 1790-1797, 2011.

Das, S. K., Jayaraman, A., and Misra, A.: Fog-induced variations in aerosol optical and physical properties over the Indo-Gangetic Basin and impact to aerosol radiative forcing, Ann. Geophys., 26, 1345-1354, doi:10.5194/angeo-26-1345-2008, 2008.

Draxler, R. R. and Rolph, G. D.: HYSPLIT (Hybrid single-particle Lagrangian Integrated Trajectory) model, http://www.arl.noaa. gov/ready/hysplit4.html, NOAA Air Resources Laboratory, Silver, Spring, MD, 2003.

Duchi, R., Cristofanelli, P., Marinoni, A., Laj, P., Marcq, S., Villani, P., Sellegri, K., Angelini, F., Calzolari, F., Gobbi, G. P., Verza, G. P., Vuillermoz, E., Sapkota, A., and Bonasoni, P.: Continuous observations of synoptic-scale dust transport at the Nepal Climate Observatory-Pyramid (5079 m a.s.1.) in the Himalayas, Atmos. Chem. Phys. Discuss., 11, 4229-4261, doi:10.5194/acpd11-4229-2011, 2011.

Eck, T. F., Holben, B. N., Reid, J. S., Dubovik, O., Smirnov, A., O'Neill, N. T., Slutsker, I., and Kinne, S.: Wavelength dependence of the optical depth of biomass burning, urban, and desert dust aerosols, J. Geophys. Res., 104, 31333-31349, 1999.

Eck, T. F., Holben, B. N., Dubovik, O., Smirnov, A., Slutsker, I., Lobert, J. M., and Ramanathan, V.: Column-integrated aerosol optical properties over the Maldives during the northeast monsoon for 1998-2000, J. Geophys. Res., 106, 28555-28566, 2001.

Eck, T. F., Holben, B. N., Ward, D. E., Mukelabai, M. M., Dubovik, O., Smirnov, A., Schafer, J. S., Hsu, N. C., Piketh, S. J., Queface, A., Le Roux, J., Swap, R. J., and Slutsker, I.: Variability of biomass burning aerosol optical characteristics in southern Africa during SAFARI 2000 dry season campaign and a comparison of single scattering albedo estimates from radiometric measurements, J. Geophys. Res., 108, 8477, doi:10.1029/2002JD002321, 2003.

Eck, T. F., Holben, B. N., Dubovic, O., Smirnov, A., Goloub, P., Chen, H. B., Chatenet, B., Gomes, L., Zhang, X. Y., Tsay, S. C., Ji, Q., Giles, D., and Slutsker, I.: Columnar aerosol opti- cal properties at AERONET sites in central eastern Asia and aerosol transport to the tropical mid-Pacific, J. Geophys. Res., 110, D06202, doi:10.1029/2004JD005274, 2005.

Eck, T. F., Holben, B. N., Reid, J. S., Giles, D. M., Rivas, M. A., Singh, R. P., Tripathi, S. N., Bruegge, C. J., Platnick, S., Arnold, G. T., Krotkov, N. A., Carn, S. A., Sinyuk, A., Dubovik, O., Arola, A., Schafer, J. S., Artaxo, P., Smirnov, A., Chen, H., and Goloub, P.: Fog- and cloud-induced aerosol modification observed by the Aerosol Robotic Network(AERONET), J. Geophys. Res., 117, D07206, doi:10.1029/2011JD016839, 2012.

El-Askary, H., Gautam, R., Singh, R. P., and Kafatos, M.: Dust storms detection over the Indo-Gangetic basin using multi sensor data, Adv. Space Res., 37, 728-733, 2006.

Ferrare, R., Ismail, S., Browell, E., Brackett, V., Clayton, M., Kooi, S., Melfi, S. H., Whitemann, D., Schwemmwer, G., Evans, K., Russell, P., Livingston, J., Schmid, B., Holben, B., Remer, L., Smirnov, A., and Hobbes, V.: Comparison of aerosol optical properties and water vapor among ground and airborne lidars and sun photometers during TARFOX, J. Geophys. Res., 105, 99179933, 2000.

Ganguly, D., Jayaraman, A., and Gadhavi, H.: In situ ship cruise measurements of mass concentration and size distribution of aerosols over Bay of Bengal and their radiative impacts, J. Geophys. Res., 110, D06205, doi:10.1029/2004JD005325, 2005.

Gautam, R., Hsu, C. N., Kafatos, M., and Tsay, S.-C.: Influences of winter haze on fog/low cloud over the Indo-Gangetic Plains, J. Geophys. Res., 112, D05207, doi:10.1029/2005JD007036, 2007.

Gautam, R., Hsu, N. C., Lau, K.-M., and Kafatos, M.: Aerosol and rainfall variability over the Indian monsoon region: distributions, trends and coupling, Ann. Geophys., 27, 3691-3703, doi:10.5194/angeo-27-3691-2009, 2009a.

Gautam, R., Liu, Z., Singh, R. P., and Hsu, N. C.: Two contrasting dust-dominant periods over India observed from MODIS and CALIPSO data, Geophys. Res. Lett., 36, L06813, doi:10.1029/2008GL036967, 2009b.

Gobbi, G. P., Kaufman, Y. J., Koren, I., and Eck, T. F.: Classification of aerosol properties derived from AERONET direct sun data, Atmos. Chem. Phys., 7, 453-458, doi:10.5194/acp-7-453-2007, 2007.

Gogoi, M. M., Moorthy, K. K., Babu, S. S., Bhuyan, P. K.: Climatology of columnar aerosol properties and the influence of synoptic conditions: First-time results from the northeastern region of India, J. Geophys. Res., 114, D08202, doi:10.1029/2008JD010765, 2009.

Gummeneni, S., Yusup, Y. B., Chavali, M., and Samadi, S. Z.: Source apportionment of particulate matter in the ambient air of Hyderabad city, India, Atmos. Res., 101, 752-754, 2011.

Harris, J. M. and Kahl, J. D.: A descriptive atmospheric transport climatology for the Mauna Loa Observatory, using clustered trajectories, J. Geophys. Res., 95, 13651-13667, 1990.

IPCC: Summary for Policymakers, in: Climate Change 2007: The Physical Science Basis. Contribution of Working Group I to the Fourth Assessment Report of the Intergovernmental Panel on Climate Change, edited by: Solomon, S., Qin, D., Manning, M., Chen, Z., Marquis, M., Averyt, K. B., Tignor, M., and Miller, H. L., Cambridge University Press, Cambridge, United Kingdom and New York, NY, USA, 2007.

Jayaraman, A., Gadhavi, H., Ganguly, D., Misra, A., Ramachandran, S., and Rajesh, T. A.: Spatial variations in aerosol charac- 
teristics and regional radiative forcing over India: Measurements and modeling of 2004 road campaign experiment, Atmos. Environ., 40, 6504-6515, 2006.

Kalapureddy, M. C. R., Kaskaoutis, D. G., Ernest Raj, P., Devara, P. C. S., Kambezidis, H. D., Kosmopoulos, P. G., and Nastos, P. T.: Identification of aerosol type over the Arabian Sea in the premonsoon season during the ICARB campaign, J. Geophys. Res., 114, D17203, doi:10.1029/2009JD011826, 2009.

Kaskaoutis, D. G., Kambezidis, H. D., Hatzianastassiou, N., Kosmopoulos, P. G., and Badarinath, K. V. S.: Aerosol climatology: dependence of the Ångström exponent on wavelength over four AERONET sites, Atmos. Chem. Phys. Discuss., 7, 7347-7397, doi:10.5194/acpd-7-7347-2007, 2007.

Kaskaoutis, D. G., Badarinath, K. V. S., Kharol, S. K., Sharma, A. R., and Kambezidis, H. D.: Variations in the aerosol optical properties and types over the tropical urban site of Hyderabad, India, J. Geophys. Res., 114, D22204, doi:10.1029/2009JD012423, 2009.

Kaskaoutis, D. G., Kalapureddy, M. C. R., Krishna Moorthy, K., Devara, P. C. S., Nastos, P. T., Kosmopoulos, P. G., and Kambezidis, H. D.: Heterogeneity in pre-monsoon aerosol types over the Arabian Sea deduced from ship-borne measurements of spectral AODs, Atmos. Chem. Phys., 10, 4893-4908, doi:10.5194/acp-10-4893-2010, 2010.

Kaskaoutis, D. G., Kumar Kharol, S., Sinha, P. R., Singh, R. P., Kambezidis, H. D., Rani Sharma, A., and Badarinath, K. V. S.: Extremely large anthropogenic-aerosol contribution to total aerosol load over the Bay of Bengal during winter season, Atmos. Chem. Phys., 11, 7097-7117, doi:10.5194/acp-11-70972011, 2011.

King, M. D.: Sensitivity of constrained linear inversion to the selection of Lagrange multiplier, J. Atmos. Sci., 39, 1356-1369, 1982.

King, M. D., Byrne, D. M., Herman, B. M., and Reagen, J. A.: Aerosol size distribution obtained by inversion of spectral optical depth measurements, J. Atmos. Sci., 35, 2153-2167, 1978.

Lawrence, M. G. and Lelieveld, J.: Atmospheric pollutant outflow from southern Asia: a review, Atmos. Chem. Phys., 10, 1101711096, doi:10.5194/acp-10-11017-2010, 2010.

Lubin, D., Satheesh, S. K., McFarquar, G., and Heymsfield, A. J.: Longwave radiative forcing of Indian Ocean tropospheric aerosol, J. Geophys. Res., 107, 8004, doi:10.1029/2001JD001183, 2002.

Mishchenko, M. I., Travis, L. D., Kahn, R. A., and West, R. A.: Modeling Phase Functions for dustlike tropospheric aerosols using a shape mixture of randomly oriented polydisperse spheroids, J. Geophys. Res., 102, 16831-16847, 1997.

Moorthy, K. K., Nair, P. R., and Murthy, B. V. K.: Size distribution of coastal aerosols: Effects of local sources and sinks, J. Appl. Meteorol., 30, 844-852, 1991.

Moorthy, K. K., Babu, S. S., and Satheesh, S. K.: Aerosol characteristics and ratiative impacts over the Arabian Sea during the Intermonsoon season: Results from ARMEX field campaign, J. Atmos. Sci., 62, 192-206, 2005.

Moorthy, K. K., Nair, V. S., Babu, S. S., and Satheesh, S. K.: Spatial and vertical heterogeneities in aerosol properties over oceanic regions around India: Implications for radiative forcing, Q. J. Roy. Meteorol. Soc., 135, 2131-2145, 2009.
Morys, M., Mims III, F. M., Hagerup, S., Anderson, S. E., Baker, A., Kia, J., and Walkup, T.: Design calibration, and performance of MICROTOPS II handheld ozone monitor and Sun photometer, J. Geophys. Res., 106, 14573-14582, 2001.

Nair, V. S., Moorthy, K. K., and Babu, S. S.: Size segregated aerosol mass concentration measurements over the Arabian Sea during ICARB, J. Earth Syst. Sci., 117, 315-323, 2008.

O’Neill, N. T., Dubovic, O., and Eck, T. F.: Modified Ångström exponent for the characterization of submicrometer aerosols, Appl. Optics, 40, 2368-2375, 2001.

Prasad, A. K., Singh, R. P., and Kafatos, M.: Influence of coal based thermal power plants on aerosol optical properties in the Indo-Gangetic basin, Geophys. Res. Lett., 33, L05805, doi:10.1029/2005GL023801, 2006.

Prasad, A. K. and Singh, R. P.: Changes in aerosol parameters during major dust storm events (2001-2005) over the Indo-Gangetic Plains using AERONET and MODIS data, J. Geophys. Res., 112, D09208, doi:10.1029/2006JD007778, 2007a.

Prasad, A. K. and Singh R. P.: Comparison of MISR-MODIS aerosol optical depth over Indo-Gangetic basin during the winter and summer seasons (2000-2005), Rem. Sens. Environ., 107, 109-119, 2007b.

Prasad, A. K., Singh, R. P., and Kafatos, M.: Influence of coal-based thermal power plants on the spatial-temporal variability of tropospheric $\mathrm{NO}_{2}$ column over India, Environ. Monit. Assess, 184, 1891-907, 2011.

Pruppacher, H. R. and Klett, J. D.: Microphysics of Clouds and Precipitation, D. Reidel, Dordrecht, The Netherlands, 1978.

Ramachandran, S. and Jayaraman, A.: Premonsoon aerosol loading and size distribution over the Arabian Sea and the Tropical Indian Ocean, J. Geophys. Res., 107, 4738, doi:10.1029/2002JD002386, 2002.

Ramanathan, V., Crutzen, P. J., Lelieveld, J., Mitra, A. P., Althausen, D., Anderson, J., Andreae, M. O., Cantrell, W., Cass, G. R., Chung, C. E., Clarke, A. D., Coakley, J. A., Collins, W. D., Conant, W. C., Dulac, F., Heintzenberg, J., Heymsfield, A. J., Holben, B., Howell, S., Hudson, J., Jayaraman, A., Kiehl, J. T., Krishnamurti, T. N., Lubin, D., McFarquhar, G., Novakov, T., Ogren, J. A., Podgorny, I. A., Prather, K., Priestley, K., Prospero, J. M., Quinn, P. K., Rajeev, 20 K., Rasch, P., Rupert, S., Sadourny, R., Satheesh, S. K., Shaw, G. E., Sheridan, P., and Valero, F. P. J.: Indian Ocean Experiment: An integrated analysis of the climate and the great Indo-Asian haze, J. Geophys. Res., 106, 28371-28398, 2001.

Reid, J. S., Eck, T. F., Christopher, S. A., Hobbs, P. V., and Holben, B. N.: Use of the Ångström exponent to estimate the variability of optical and physical properties of aging smoke particles in Brazil, J. Geophys. Res., 104, 27473-27489, 1999.

Schuster, G. L., Dubovik, O., and Holben, B. N.: Angstrom exponent and bimodal aerosol size distributions, J. Geophys. Res., 111, D07207, doi:101029/2005JD006328, 2006.

Sinha, P. R., Manchanda, R. K., Subbaro, J. V., Dumka, U. C., Sreenivasan, S., Suresh Babu, S., and Moorthy, K. K.: Spatial distribution and vertical structure of the MABL aerosols over the Bay of Bengal during winter: Results from W-ICARB experiment, J. Atmos. Solar Terr. Phys., 73, 430-438, 2011. 